\title{
Assessing Nominal Income Rules for Monetary Policy with Model and Data Uncertainty
}

\author{
Glenn D. Rudebusch* \\ Federal Reserve Bank of San Francisco
}

October 2000

\begin{abstract}
Nominal income rules for monetary policy have long been debated, but two issues are of particular recent interest. First, there are questions about the performance of such rules over a range of plausible empirical models - especially models with and without explicit rational inflation expectations. Second, there are questions about the performance of these rules in real time using the type of data that is actually available contemporaneously to policymakers rather than final revised data. This paper determines optimal monetary policy rules in the presence of such model uncertainty and real-time data uncertainty and finds only a limited role for nominal output growth.
\end{abstract}

\footnotetext{
*Homepage: www.sf.frb.org/econrsrch/economists/grudebusch.html; email: Glenn.Rudebusch@sf.frb.org; address: 101 Market Street, San Francisco, CA, 94105. I thank Henrik Jensen, Ben McCallum, Lars Svensson, and other participants at the 1999 ECB/CFS conference in Frankfurt for helpful comments, as well as many colleagues in the Federal Reserve System - particularly, Gary Anderson, Bob Tetlow, and John Williams. In addition, the editor and several referees also made helpful contributions. Niloofar Badie and Kirran Bari provided excellent research assistance. The views expressed in this paper do not necessarily reflect those of the Federal Reserve Bank of San Francisco or the Federal Reserve System.
} 


\section{Introduction}

Monetary policy rules that focus on smoothing out fluctuations in nominal income or nominal output have been advocated by many economists, including Gordon (1985), McCallum (1988, 1997), Hall and Mankiw (1994), and Feldstein and Stock (1994). At a very basic level, nominal income targeting appears to have two desirable features as a strategy for monetary policy. First, it automatically takes into account movements in both prices and real output, which in practice are the two macroeconomic variables that central banks care about most. Second, nominal income can serve as a long-run nominal anchor for monetary policy. Such an anchor is important under the usual presumption that the monetary authority cannot influence the real economy in the long run and so should focus on stabilizing a nominal variable.

Recently, two quite disparate developments have also boosted interest in nominal output targeting. ${ }^{1}$ The formation of a new monetary authority in Europe - the European Central Bank (ECB) - has spurred a lively debate about the most appropriate strategy for European monetary policy (e.g., Rudebusch and Svensson, 2000). The announced ECB strategy contains an element of monetary targeting, which is closely related to nominal output targeting. Indeed, the ECB (1999) has explicitly derived its 4-1/2 percent reference value for M3 growth from a desired growth rate for nominal output - which is calculated as the sum of an inflation target of less than 2 percent and a forecasted trend growth rate of real output of 2 to $2-1 / 2$ percent - along with a small adjustment for a secular decline in velocity. As many have noted, both monetary targeting and nominal output targeting should produce similar outcomes if there are no large shifts in velocity. Thus, the ECB's announced monetary strategy provides support for consideration of nominal output targeting; conversely, the ECB's strategy also obtains some further legitimacy from any favorable research results on nominal output targeting.

A second boost to research in nominal income targeting has come from the recent behavior of the U.S. economy. For the past few years, most macroeconomic forecasters have made an unusual string of prediction errors in the United States-both overpredicting inflation and underpredicting output growth (Brayton, Roberts, and Williams, 1999, and Rudebusch, 1999). These errors raise questions about our understanding of the current dynamics of inflation and output and may signal a structural change in the economy. In particular, in light of the apparent large amount of uncertainty about the level of potential output and the dynamics of the U.S.

\footnotetext{
${ }^{1}$ In this paper, nominal income is synonymous with nominal output, though in the real world, the two series are obtained from different data sources and the "statistical" discrepancy between them may be non-trivialespecially in real time.
} 
economy, McCallum (1998), Orphanides (1999), and Trehan (1999) suggest that monetary policy should focus on nominal output growth because such a strategy does not rely on uncertain estimates of the level of the output gap.

Still, there remain many skeptics. The most forceful argument against nominal output targeting is based simply on a view that the timing of real output and inflation responses to monetary policy actions are quite different, with the effects on output showing up much sooner than those on inflation. This view of the monetary transmission mechanism is common among both academics (using structural and atheoretical methods) as well as policymakers (e.g., Bank of England, 1999). Unfortunately, a policy rule that reacts to nominal output necessarily responds in an identical fashion to fluctuations in real output growth and inflation and so does not perform well with such asynchronous monetary transmission lags. Notably, Ball (1999) and Svensson (1999a) show that in a simple backward-looking aggregate demand and supply model where monetary policy affects output with a shorter lag than inflation, nominal output targeting leads to dynamic instability, that is, infinite variances for output and inflation.

However, this argument has not gone unchallenged. In particular, McCallum (1997) notes that the Ball-Svensson result does not generalize to certain macroeconomic models; specifically, he criticizes their inflation specification, which depends only on realizations of past inflation rather than expectations of future inflation. McCallum finds that nominal output targeting is not de-stabilizing in a simple theoretical, forward-looking, rational expectations model, so uncertainty about the dynamics of the economy may allow one to favor nominal output targeting.

To resolve these various questions about the desirability of nominal output rules for monetary policy, this paper explores the performance of such rules allowing for both uncertainty about the real-time output gap and uncertainty about the appropriate model. This investigation is conducted using a "New Keynesian" model of output and inflation, which is introduced in the next section. In the past decade, a broad consensus has emerged in macroeconomics that such a model provides a useful framework for analyzing monetary policy. ${ }^{2}$ In particular, this specification generalizes and nests the models used by Ball (1999), McCallum(1997), and Svensson (1999a). However, a key issue is whether the data can resolve at least some of the uncertainty among the various versions of the model; thus, an empirically estimated version of the new Keynesian model will be employed.

\footnotetext{
${ }^{2}$ Indeed, such a framework is termed the "conventional wisdom" in Svensson (1999b, p. 609) and is held in similar esteem in, for example, Clarida, Gali, Gertler (2000), McCallum and Nelson (1999a, b), Rotemberg and Woodford (1999), and several other contributions in Taylor (1999).
} 
Section 3 introduces the three policy rules of interest. Two of these rules respond to the growth of nominal output and have been advocated in the literature. The third, a benchmark for comparison, is a simple version of the Taylor (1993) rule that reacts to the output gap and inflation. Section 4 examines the performance of these three rules in the estimated New Keynesian model. In order to address the earlier debate about model specification, the degree of inflation persistence is varied over a range from completely backward-looking or adaptive expectations to completely forward-looking expectations. Almost without exception, the nominal income rules perform quite poorly relative to the Taylor rule.

The use of the Taylor rule introduces the second issue of recent contention; namely, the uncertainty about the measurement of the output gap and the likely performance of the Taylor rule in real time. A real-time analysis (as defined by Diebold and Rudebusch, 1991) refers to the use of sequential information sets that were actually available as history unfolded. Mimicking a real-time analysis is crucial for assessing policy rules, especially those like the Taylor rule that rely on variables such as the output gap that may be very difficult to estimate contemporaneously (see Clarida, Gali, and Gertler, 2000, and Rudebusch, 1999). Therefore, section 5 incorporates such real-time data uncertainty into the evaluation of the policy rules.

Finally, section 6 considers a hybrid rule that augments the Taylor rule with a nominal income response in order to assess the marginal contribution of the latter. Section 7 provides concluding remarks.

\section{An Empirical New Keynesian Model}

This section describes the empirical New Keynesian specification that is used in the analysis below. The discussion is conducted in terms of the key aggregate relationships; however, much of the appeal of the New Keynesian model is that these relationships have direct foundations in a dynamic general equilibrium model with temporary nominal price rigidities. For explicit derivations and discussion, see Woodford (1996), Goodfriend and King (1997), Walsh (1998), Clarida, Gali, and Gertler (2000), Jensen (1999), and the references above in footnote 1.

\subsection{Inflation}

The consensus on a theoretical New Keynesian model of inflation can be represented by the equation

$$
\pi_{t}=\mu_{\pi} E_{t} \pi_{t+1}+\left(1-\mu_{\pi}\right) \pi_{t-1}+\alpha_{y} y_{t}+\varepsilon_{t}
$$


where $\pi_{t}$ is the inflation rate, $y_{t}$ is the output gap, $E_{t} \pi_{t+1}$ is the expectation of period $t+1$ inflation conditional on a time $t$ information set, and $0 \leq \mu_{\pi} \leq 1$. In the recent debate about nominal income rules, for example, Ball (1999), Svensson (1999a), and McCallum (1997) all agree that equation (2.1) provides a useful theoretical structure for policy analysis. However, they differ on the appropriate value of $\mu_{\pi}$, that is, the degree to which current inflation is determined by explicitly rational expectations of future inflation. Ball and Svensson set $\mu_{\pi}=0$, so current inflation is determined by a lagged or adaptive response to past inflation. ${ }^{3}$ In contrast, McCallum considers $\mu_{\pi}=1$, so prices are set with no reference to past inflation. As McCallum stresses, this difference in the degree of forward-looking behavior in the inflation equation is the key issue separating his results on the performance and dynamic stability of a nominal income rule from those of Ball and Svensson. ${ }^{4}$

As a theoretical matter, the value of $\mu_{\pi}$ is not clearly determined. From the well-known models of price-setting behavior of Rotemberg (1982), Calvo (1983), and Taylor (1980) it is possible to derive an inflation equation with $\mu_{\pi} \approx 1$ (see Roberts, 1995). However, many authors assume that with realistic costs of adjustment and overlapping price and wage contracts there will be some inertia in inflation, so $\mu_{\pi}$ will be less than one (Svensson, 1999a, Fuhrer and Moore, 1995, and Fuhrer, 1997). ${ }^{5}$

Empirical evidence on the value of $\mu_{\pi}$ is thus crucial. To obtain such evidence, I estimate a version of (2.1) with quarterly data. Of course, given the institutional length of price contracts in the real world, the one-period leads and lags in the theoretical version (2.1) typically represent annual leads and lags (e.g., Svensson 1999b and Smets 2000). Thus, at a quarterly frequency, longer leads and lags are appropriate. In addition, at a quarterly frequency, the contemporaneous timing of the annual equation (2.1) becomes less tenable given real-world recognition, processing, and adjustment lags. Thus, I reformulate (2.1) as

$$
\pi_{t}=\mu_{\pi} E_{t-1} \bar{\pi}_{t+3}+\left(1-\mu_{\pi}\right)\left(\alpha_{\pi 1} \pi_{t-1}+\alpha_{\pi 2} \pi_{t-2}+\alpha_{\pi 3} \pi_{t-3}+\alpha_{\pi 4} \pi_{t-4}\right)+\alpha_{y} y_{t-1}+\varepsilon_{t},
$$

where $E_{t-1} \bar{\pi}_{t+3}$ represents the expectation of average inflation over the next year. (Specifically, $\bar{\pi}_{t}$ is four-quarter inflation, i.e., $\frac{1}{4} \Sigma_{j=0}^{3} \pi_{t-j}$.) Specification (2.2) uses a one-quarter lag on the output gap and a one-quarter lag in the information set for the formation of expectations.

\footnotetext{
${ }^{3}$ Of course, such a "backward-looking" specification may implicitly represent rational expectations given the structure of the economy.

4 Also, see Dennis (1999a) and Rudebusch and Svensson (2000).

${ }^{5}$ As an alternative explanation, if some fraction of the population bases their inflation expectations solely on lagged inflation, then $\mu_{\pi}$ would also be less than one (see Roberts 1998). Indeed, one interpretation of Ball's model with $\mu_{\pi}=0$ is that expectations are completely adaptive.
} 
Such lags are common in the theoretical literature (see Svensson, 1999a, and Rotemberg and Woodford, 1999); however, as described in the working paper versions of this article similar results were obtained with a variety of alternative specifications (including the contemporaneous timing of expectations). ${ }^{6}$ Note that with $\mu_{\pi}=0$, equation (2.2) becomes an empirical version of the adaptive expectations model in Ball (1999) and Svensson (1999a) that is analyzed in Rudebusch and Svensson (1999) and Rudebusch (1999). Orphanides (1999) also assumes that $\mu_{\pi}=0$.

An estimated version of (2.2), using the sample period 1968:Q3 to 1996:Q4, ${ }^{7}$ is

$$
\begin{aligned}
& \pi_{t}=.29 E_{t-1} \bar{\pi}_{t+3}+(.71)\left(.67 \pi_{t-1}-.14 \pi_{t-2}+.40 \pi_{t-3}+.07 \pi_{t-4}\right)+.13 y_{t-1}+\varepsilon_{t}, \\
& \bar{R}^{2}=.82, \quad \sigma_{\varepsilon}=1.012, \quad \mathrm{DW}=1.96
\end{aligned}
$$

where $\pi_{t}$ is quarterly inflation in the GDP chain-weighted price index $\left(P_{t}\right)$ in percent at an annual rate (i.e., $\pi_{t} \equiv 4\left(p_{t}-p_{t-1}\right)$, where $p_{t}=100 \ln P_{t}$ ), and $y_{t}$ is the output gap (approximately $q_{t}-q_{t}^{*}$, where $q_{t} \equiv 100 \ln Q_{t}$ and $q_{t}^{*} \equiv 100 \ln Q_{t}^{*}$ with $Q_{t}$ defined as chain-weighted real GDP and $Q_{t}^{*}$ defined as potential GDP as estimated by the Congressional Budget Office 1995). For estimation, one-year-ahead inflation expectations are obtained from the Michigan survey of inflation expectations as in Roberts (1998) and Clark, Laxton, and Rose (1996). The appendix considers an alternative survey of inflation expectations with similar results. The hypothesis that the sum of all of the inflation coefficients equaled one (i.e., $\mu_{\pi}+\left(1-\mu_{\pi}\right) \Sigma_{j=1}^{4} \alpha_{\pi j}=1$ or $\left.\Sigma_{j=1}^{4} \alpha_{\pi j}=1\right)$, a version of the natural rate hypothesis, had a $p$-value of 0.24 , so this restriction was imposed in estimation.

This empirical inflation equation appears to be quite consistent with earlier research - even research that has not used survey-based expectations in estimation. The coefficient of particular interest is $\mu_{\pi}$, which measures the degree of explicitly forward-looking behavior. The estimate of $\mu_{\pi}=0.29$ is statistically significantly different from zero, and the estimated standard error suggests a 90 percent confidence interval for $\mu_{\pi}$ of between 0.16 and 0.42 . The point estimate of $\mu_{\pi}$-about a one-third weight on future inflation - is in the middle of the range of estimates provided by previous researchers. These researchers have used three basic techniques to obtain estimates of $\mu_{\pi}$. For example, Fuhrer (1997) estimates an equation quite similar to (2.2) using

\footnotetext{
${ }^{6}$ The best approximation with quarterly data of the annual frequency expectation $E_{t} \pi_{t+1}$ used in theoretical models is unresolved. The staggered information sets in Clark, Laxton, and Rose (1996) provide another alternative.

7 Coefficient standard errors are given in parentheses, and the standard error of the residuals and DurbinWatson statistics also are reported. The data are de-meaned, so no constant is needed.
} 
Full-Information Maximum Likelihood (in particular, closing the model with unrestricted autoregressive equations and model-consistent expectations). With a variety of different measures of the output gap, he obtains estimates for $\mu_{\pi}$ of between 0.02 and 0.20 -none of which are statistically significantly different from zero. A second (limited-information) estimation method uses instrumental variables. With this method, Fair (1993) is also unable to reject $\mu_{\pi}=0$. In contrast, three other studies (also using instrumental variables) obtain higher estimates: Chadha, Masson, and Meredith (1992) estimate $\mu_{\pi}$ equal to 0.44 with annual data for a panel of the United States and Canada; Brayton, et al. (1997) estimate $\mu_{\pi}$ to equal 0.43 for the Federal Reserve Board staff's large-scale macroeconometric model; and Roberts (1999) estimates $\mu_{\pi}$ to equal 0.28 or, after allowing for a structural break, to equal 0.42 . Finally, as above, a third estimation method uses a direct measure of expectations from surveys. For example, using the Michigan survey expectations, Clark, Laxton, and Rose (1996) estimate a $\mu_{\pi}$ of about 0.40 while Laxton et al. (1998) obtain an estimate of 0.32 for the IMF multi-country model. ${ }^{8}$ Overall, based on the estimated equation above and the set of previous empirical estimates and their standard errors, a wide plausible range for $\mu_{\pi}$ - say, an approximate 95 percent confidence interval — is probably between 0 and $0.6 .^{9}$ The size of this interval highlights the need to examine the robustness of the nominal income rule results with respect to variation in $\mu_{\pi}$.

The estimated value of $\alpha_{y}$ is also typical, and, as described below, the dynamics of this equation compare favorably to an unrestricted version. Finally, the estimated equation (2.3) appears to be fairly stable over various subsamples - an important condition for drawing inferences. For example, consider a stability test from Andrews (1993): the maximum value of the likelihood-ratio test statistic for structural stability over all possible breakpoints in the middle 70 percent of the sample. For equation (2.3), the maximum likelihood-ratio test statistic is 12.54 (in 1972:4), while the 10 percent critical value is 16.20 (from Table 1 in Andrews, 1993).

\footnotetext{
${ }^{8}$ In other countries, Gruen, Pagan, and Thompson (1999) obtain estimates of $\mu_{\pi}$ that are less than 0.2 in Australia. The Bank of England (1999, p. 91) reports an estimate of 0.175 with survey expectations in the UK, and with the Bank of Canada model, Maclean (1998) uses a $\mu_{\pi}$ value of 0.2 .

${ }^{9}$ There are empirical studies, such as McCallum and Nelson (1999a, b) and Rotemberg and Woodford (1999), that essentially impose a value of unity on $\mu_{\pi}$. Estrella and Fuhrer (1998) discuss the empirical implausibility of such specifications; also, see section 2.3 below. In addition, Gali and Gertler (1999) and Sbordone (1998) are sometimes (incorrectly) interpreted as obtaining empirical estimates of $\mu_{\pi}$ close to unity; however, the evidence in these two papers pertains to the markup of price inflation conditional on labor costs and has no relevance on its own for the value of $\mu_{\pi}$ (for further discussion, see Roberts, 1999).
} 


\subsection{Output}

The New Keynesian version of aggregate demand can be represented by an intertemporal Euler equation of the form:

$$
y_{t}=E_{t} y_{t+1}-\beta_{r}\left(i_{t}-E_{t} \pi_{t+1}-r^{*}\right)+\eta_{t},
$$

where $y_{t}$ is the output gap, $E_{t} y_{t+1}$ is the expectation of future output, $i_{t}$ is the short-term, nominal interest rate, and $r^{*}$ is the equilibrium real rate. (See McCallum and Nelson, 1999a, and Svensson, 1999a.) Again, for realism, it is widely agreed that some form of costly adjustment or habit formation must be added to the model in order to match the inertia and lagged responses that are apparent in the data, though the exact form of the resulting specification is still under debate. (See Rotemberg and Woodford, 1999, Fuhrer, 2000, McCallum and Nelson, 1999b, and Estrella and Fuhrer, 1998.) For example, Svensson (1999a) replaces $E_{t} y_{t+1}$ with a term such as $\mu_{y} E_{t-1} y_{t+1}+\left(1-\mu_{y}\right) y_{t-1}$. Unfortunately, empirical estimates of $\mu_{y}$ with quarterly data are hard to find in the literature; thus, I follow much previous analysis, notably Fuhrer and Moore (1995) and Orphanides (1999), and include only lags of output (i.e., $\mu_{y}=0$ ). However, the appendix does provide an alternative set of results based on $\mu_{y}=0.3$, which is suggested by the only available estimate with quarterly data (i.e., Fuhrer, 2000). For the issues addressed in this paper, little appears to hinge on the specification of the output equation, and the results in the appendix are similar to those displayed below. ${ }^{10}$

For empirical implementation with quarterly data, I estimate an equation of the form:

$$
y_{t}=\beta_{y 1} y_{t-1}+\beta_{y 2} y_{t-2}-\beta_{r}\left(\imath_{t-1}-E_{t-1} \bar{\pi}_{t+3}\right)+\eta_{t},
$$

where, again, $E_{t-1} \bar{\pi}_{t+3}$ represents the expectation of average inflation over the next year (obtained from survey data). Real output thus depends on its past values and on an approximate ex ante real interest rate. (The data are de-meaned, so $r^{*}$ equals zero.) The OLS estimated version of this equation using the sample period 1968:Q3 to 1996:Q4 is

$$
\begin{aligned}
& y_{t}=\begin{array}{c}
1.15 y_{t-1} \\
(.09)
\end{array}-\begin{array}{c}
.27 y_{t-2} \\
(.09)
\end{array} \\
& \bar{R}^{2}=.89, \quad \sigma_{\eta}=0.833, \quad \mathrm{DW}=2.14 .
\end{aligned}
$$

\footnotetext{
${ }^{10}$ Indeed, as noted by McCallum (1997, p. 5), the Ball and Svensson result is "purely a result of the particular Phillips curve" that those authors employ and "is independent of aggregate demand behavior." Jensen (1999) also concludes that the amount of output persistence in the aggregate demand specification has little effect on assessing the desirability of nominal income targeting.
} 
As was the case above, this output equation appears to be stable over various subsamples. The stability test from Andrews (1993) (the maximum value of the likelihood-ratio test statistic) is 9.99 (in 1974:1), while the 10 percent critical value is 12.27 .

\subsection{Examination of Model Dynamics}

It is instructive to compare the dynamics of the estimated New Keynesian structural model (2.3) and (2.6) to an unrestricted vector autoregression (VAR). While one may be deeply skeptical of the use of VARs for certain structural investigations (see Rudebusch, 1998), they can provide a simple atheoretical summary of the data and a useful benchmark of the general dynamics of a structural model. For this comparison, I use a trivariate VAR with four lags of $\pi, y$, and $i$. For example, the VAR funds rate equation regresses the funds rate on four lags of each variable as well as the contemporaneous values of the output gap and inflation. ${ }^{11}$ This VAR funds rate equation-with its interpretation as a Federal Reserve reaction function-is also added as a third equation to the structural model (2.3) and (2.6). Because this equation is shared by the VAR and the augmented structural model, any differences in dynamics between the two systems can be attributed to the output and inflation equations.

Figure 1 shows the responses of these two systems to various shocks. The impulse responses of the structural system are shown as solid lines, while the VAR impulse responses are shown as dashed lines along with their 95 percent confidence intervals as dotted lines. ${ }^{12}$ In response to a positive funds rate shock, output and inflation decline in a similar manner in each system. ${ }^{13}$ A positive output shock persists over time and boosts inflation in a like fashion in both models. The inflation shock also shows substantial persistence. Overall, the structural model and VAR impulse responses appear to be quite similar.

Thus, even though survey expectations were used to estimate the model, the model dynamics under rational expectations appear to fit the data fairly well. Indeed, Fuhrer (1997) obtains an estimated inflation equation very similar to (2.3) by essentially maximizing the fit between the autocorrelations of the model and the data implicit in Figure 1. In contrast, Figure 2 compares the impulse responses of the VAR to those from the structural model where the value of $\mu_{\pi}$ is set equal to 0.8. (Everything else about the two systems is held fixed.) This model is empirically

\footnotetext{
11 The VAR output equation regresses output on lags of $\pi, y$, and $i$. The VAR inflation equation regresses inflation on the same lags as well as the contemporaneous value of the output gap. Thus, this VAR has a Cholesky factorization with a causal order of output, inflation, and the funds rate.

12 The impulse responses of the estimated forward-looking structural system (with the VAR interest rate equation) are obtained from the reduced form which is calculated analytically as described below.

13 There is a modest, insignificant "price puzzle" exhibited by the VAR but not the structural model.
} 
implausible from the standpoint of survey expectations and, it appears, from the standpoint of fit to the data under rational expectations. The difficulty with a model with such a high degree of forward-looking inflation behavior is evident in the top three panels of Figure 2: The response of inflation is much faster in the model than appears to be the case in practice. Notably, after a positive shock to the funds rate, the inflation rate counterfactually jumps down immediately to a lower level. Also, after an inflation shock, the inflation rate returns to the baseline level after two or three quarters with essentially no deviation in output. Such a low sacrifice ratio is quite implausible. (See Estrella and Fuhrer, 1998.)

\section{Monetary Policy Rules}

Given the empirical model described above, I examine the performance of three specific simple policy rules that have been recommended by previous authors as good guides for monetary policy. Two of these rules respond to the growth rate of nominal output. ${ }^{14}$ The first such nominal income rule, denoted here as the $N 1$ rule, is the one advocated by Orphanides (1999):

$$
i_{t}=r^{*}+\bar{\pi}_{t}+g_{\bar{x}}\left(\bar{x}_{t}-\bar{x}_{t}^{*}\right)
$$

This rule sets the nominal interest rate equal to the equilibrium real interest rate $\left(r^{*}\right)$ plus inflation $\left(\bar{\pi}_{t}\right)$ plus some fraction $g_{\bar{x}}$ of the deviation of four-quarter nominal output growth from its target rate, denoted $\bar{x}_{t}-\bar{x}_{t}^{*}$. Note that nominal output growth can, of course, be rewritten as the sum of inflation and real output growth, $\bar{x}_{t}-\bar{x}_{t}^{*}=\bar{\pi}_{t}+\Delta_{4} q_{t}-\pi^{*}-\Delta_{4} q_{t}^{*}$, where $\Delta_{4} q_{t}=q_{t}-q_{t-4}$ and $\Delta_{4} q_{t}^{*}$ is the target (trend) growth rate of potential output. ${ }^{15}$

The second nominal income rule, denoted as the N2 rule, is one suggested by McCallum and Nelson (1999a):

$$
i_{t}=g_{x}\left(x_{t}-x_{t}^{*}\right)+\rho i_{t-1}
$$

This rule responds to the deviation of quarterly nominal output growth (at an annual rate) from its target. ${ }^{16}$ In terms of quarterly inflation and real output growth (at an annual rate),

\footnotetext{
${ }^{14}$ It is important to note that these are instrument rules that "respond to nominal output." They are not rules that actually "target" nominal output, as discussed in Rudebusch and Svensson (1999) and Svensson (1999b). Nominal output targeting rules would involve the minimization of a loss function over expected future deviations of nominal output from a desired level. Nominal output targeting also could be expressed as a rule that changes the interest rate in response to many variables (particularly, the determinants of nominal income) in order to produce a desired nominal income path. This strategy is examined in Rudebusch and Svensson (2000) and is found to perform quite poorly, but Jensen (1999) obtains more favorable results.

${ }_{15}$ Nominal output is defined as $N_{t}=P_{t} Q_{t}$, so $\bar{x}_{t}=100\left(\ln N_{t}-\ln N_{t-4}\right)=\bar{\pi}_{t}+\Delta_{4} q_{t}$. Similarly, quarterly nominal output growth (at an annual rate) is defined as $x_{t}=400\left(\ln N_{t}-\ln N_{t-1}\right)=\pi_{t}+4 \Delta q_{t}$.

${ }^{16}$ Judd and Motley (1992) also examine this rule with $\rho=1$.
} 
$x_{t}-x_{t}^{*}=\pi_{t}-\pi^{*}+4 \Delta q_{t}-4 \Delta q_{t}^{*}$. The $\mathrm{N} 2$ rule also responds to the lagged funds rate in an autoregressive fashion. (Such "interest rate smoothing" has been recommended by Levin, Wieland, and Williams, 1999, and Woodford, 1999; however, Rudebusch, 2000, shows that the historical evidence for such smoothing is actually quite weak.)

As a benchmark to evaluate the performance of these nominal output rules, I also consider a static Taylor-type rule (denoted as the $T$ rule):

$$
i_{t}=r^{*}+\bar{\pi}_{t}+g_{\pi}\left(\bar{\pi}_{t}-\pi^{*}\right)+g_{y} y_{t}
$$

which sets the nominal interest rate equal to the real equilibrium rate $\left(r^{*}\right)$ plus inflation and some fraction $g_{\pi}$ of four-quarter inflation deviations from target and some fraction $g_{y}$ of the output gap. This rule performs well in a variety of models (see Taylor, 1999) and as a simple two-parameter rule is the obvious alternative to the N1 and N2 rules.

In analyzing the performance of these rules, the actual numerical values chosen for $r^{*}$ and $\pi^{*}$ do not affect the results, which are based on the second moments of the goal variables in a linear model. Following standard normalizations (Rudebusch and Svensson 1999), I set $r^{*}$ and $\pi^{*}$ equal to zero. However, the use of the normalization $r^{*}=0$ for the $\mathrm{T}$ and N1 rules has the important implication that the policymaker knows the true equilibrium real rate embodied in the IS curve (2.5) and incorporates this knowledge into the setting of rates. Indeed, a possible advantage of the $\mathrm{N} 2$ rule is that it does not rely on knowledge of $r^{*}$. However, as shown in Rudebusch (1999), uncertainty about $r^{*}$ in implementing rules such as T and N1 is of little importance in this framework in terms of altering the optimal rule coefficients or the expected loss.

Similarly, in the next two sections, I also assume that the trend growth rate of potential output is known to equal zero (i.e., $\Delta q_{t}^{*}=\Delta_{4} q_{t}^{*}=0$ ), which implies that target nominal output growth is also known to be zero (i.e., $x_{t}^{*}=\bar{x}_{t}^{*}=0$ ). This assumption is relaxed in section 6 , when uncertainty about the growth rate of potential output is introduced (which affects the gap between actual and desired nominal output growth in the N1 and N2 rules).

These rules are simple because they can be written in terms of only a few variables. In contrast, the fully optimal rule would involve all of the state variables of the model (see Rudebusch and Svensson, 1999, and Williams, 1999). However, given the constraint on the form of the rule, the parameters of each of the three simple rules are chosen so as to minimize the expected loss. Deriving the optimal form of this rules requires an objective function, and I use a fairly standard one in which the central bank is assumed to minimize the variation in inflation around its target 
$\pi^{*}$, in the output gap, and in changes in the interest rate (see Rudebusch and Svensson, 1999, and Clarida, Gali, and Gertler, 2000). Specifically, expected loss equals the weighted sum of unconditional variances,

$$
\mathrm{E}\left[L_{t}\right]=\operatorname{Var}\left[\bar{\pi}_{t}-\pi^{*}\right]+\lambda \operatorname{Var}\left[y_{t}\right]+\nu \operatorname{Var}\left[\Delta i_{t}\right]
$$

where $\Delta i_{t}=i_{t}-i_{t-1}$, and the parameters $\lambda \geq 0$ and $\nu \geq 0$ are the relative weights on output stabilization and interest rate smoothing, respectively, with respect to inflation stabilization. Following Rudebusch and Svensson (1999) and Rudebusch (1999), I set $\lambda=1$ and $\nu=0.5$ as a baseline case but consider some alternatives in the next section.

Finally, it should be noted that the results in this paper are obtained with a rational expectations "commitment" solution of the forward-looking structural system of aggregate demand, aggregate supply, and a policy rule. ${ }^{17}$ That is, the policy rule is assumed to be perfectly credible, so agents know the rule and assume (correctly) that it will be followed. The use of simple policy rules may aid in such a commitment. In addition, the solution takes no account of the fact that the nominal interest rate is bounded from below by zero. The imposition of such a constraint is discussed in Rudebusch and Svensson (1999) and Reifschneider and Williams (1999).

\section{Model Uncertainty}

Bennett McCallum $(1988,1998)$ has been an important proponent of the principle of robustness, specifically, that a policy rule should yield reasonably good outcomes in a wide variety of macroeconomic specifications. Robust policy rules are preferred because of uncertainty regarding the exact representation of the economy. Still, as noted above, there is a broad consensus that the aggregate demand and supply framework described in section 2 is a useful one for analyzing policy rules. An important remaining unresolved issue is the degree to which inflation is explicitly forward-looking in a model-consistent fashion. In this section, I investigate the performance and robustness of the policy rules over a range of such forward-looking behavior. (In addition, the robustness of the rules to forward-looking output terms in the output equation is considered in the appendix.)

Table 1 examines the performance of the T, N1, and N2 rules assuming the loss function (3.4) and the model (2.3) and (2.6). The three panels in the table present results for the cases $\mu_{\pi}=0.0$,

\footnotetext{
17 Specifically, results are obtained using the "AIM" algorithm (Anderson and Moore, 1985, and available at http://www.bog.frb.fed.us/pubs/oss/oss4/aimindex.html). This algorithm provides the reduced-form solution to the linear rational expectations model, from which it is straightforward to compute the relevant variances. The discretion solution to this model is considered in Dennis (1999b).
} 
$\mu_{\pi}=0.3$, and $\mu_{\pi}=0.6$ (the other parameters in the model are fixed). The estimation results above favor the intermediate value of $\mu_{\pi}=0.3$; however, the range of other empirical estimates described above and the importance of investigating rule robustness recommend consideration of a wide range of values for $\mu_{\pi}$. The case with $\mu_{\pi}=0.0$ (panel A) is important because the inflation equation has completely adaptive expectations and is an empirical counterpart to the theoretical model used by Ball (1999) and Svensson (1997). As noted above, the very upper end of the plausible empirical range of $\mu_{\pi}$ is 0.6 , and that is the case considered in panel $\mathrm{C}$.

Thus, Table 1 goes to the heart of the debate between Ball (1999), Svensson (1999a), and McCallum (1997). In panel A, with $\mu_{\pi}=0.0$, the caution expressed by Ball and Svensson about the performance of nominal income rules is apparent. In the first line, the Taylor-type $\mathrm{T}$ rule (with optimal coefficients given in parentheses) has an expected loss of 9.76 with unconditional standard deviations of inflation, output, and interest rates of $\operatorname{Std}\left[\bar{\pi}_{t}\right]=1.98, \operatorname{Std}\left[y_{t}\right]=2.07$, and $\operatorname{Std}\left[\Delta i_{t}\right]=1.75$. In contrast, the N1 and N2 rules do substantially worse with losses of 14.34 and 16.67, respectively. Under a strict interpretation, however, the Ball and Svensson result of the dynamic instability of nominal income rules does not generalize to this model with adaptive expectations but longer, empirically plausible lags. Still, the spirit of their result does endure, as the relative performance of the nominal income rule appears to deserve Ball's (1999) term "disastrous". 18

Panels $\mathrm{B}$ and $\mathrm{C}$ explore whether adding rational expectations to the inflation dynamics improves the relative performance of nominal output rules as suggested by McCallum. Again, as a general statement, this does not appear to be true. The performance of the nominal output rules relative to the Taylor rule actually deteriorates a bit as $\mu_{\pi}$ increases from zero to 0.3. Still, at very high levels of $\mu_{\pi}$, the three rules produce much more similar volatilities and losses. This result is apparent in Figure 3, which graphs the expected loss of the optimal forms of the three rules for the entire zero-to-one range of $\mu_{\pi}$. McCallum appears to be correct in asserting that with high levels of explicitly forward-looking price-setting behavior nominal output rules are a reasonable alternative to the Taylor rule. Still, a crucial issue in resolving the debate about good policy rules is whether Ball or McCallum consider an empirically more relevant case. As should be clear from the empirical evidence summarized above, it is very unlikely that $\mu_{\pi}$ is greater than 0.6; therefore, from Figure 1, Ball's conclusions about the performance of nominal output

${ }^{18}$ This is consistent with the earlier results of Taylor (1985) and Judd and Motley (1992). As Taylor (1985, p. 81) notes, "Nominal GNP rules that focus solely on the growth rate could worsen business-cycle fluctuations by always causing the economy to overshoot its equilibrium after shocks." Such overshooting is apparent in the impulse responses to shocks described below. 
rules for monetary policy seem appropriately pessimistic.

In this regard, it is also instructive to examine the impulse responses of the model. Figure 4 displays the responses of output, inflation, and the funds rate to an output shock for the three policy rules under the assumption that $\mu_{\pi}=0.3$. Two features are of particular note. First, the fluctuations of output and inflation are not sychronized, with movements in inflation trailing those in output. Again, this reflects the persistence of inflation evident in the VAR summary of the data in Figure 1. Second, with the nominal income rules, there is a sustained oscillation in the economy, which reflects the higher variability evident for this case in Table 1 . Figure 5 provides an extreme alternative - the case with $\mu_{\pi}=0.8$. In this case, inflation has very little persistence and, counterfactually, appears synchronized with output. All three of the rules are easily able to damp economic fluctuations in this case.

The three panels of Figure 6 examine alternative parameterizations of the loss function. The above results assumed that the relative weights on output and interest rate volatility are $\lambda=1$ and $\nu=0.5$. As shown in Figure 6, setting $\lambda$ to 2 or 0.5 or raising $\nu$ to 2 does not change the results. Figure 7 provides a more conventional view of alternative loss functions (e.g., Rudebusch and Svensson, 1999) by showing the tradeoff between output $\left(y_{t}\right)$ and inflation $\left(\bar{\pi}_{t}\right)$ volatility as $\lambda$ is varied from 0.2 to 9 . For the model with $\mu_{\pi}=0$, the usual tradeoff exists for all three rules: A higher output variability and lower inflation variability is chosen as $\lambda$ decreases, though the $\mathrm{T}$ rule generates the most favorable outcome. For the model with $\mu_{\pi}=0.6$, the tradeoffs look quite different. The T rule tradeoff is essentially vertical because with a forward-looking (meanreverting) inflation process the rule can stabilize inflation independently of output; thus, the $\lambda$ tradeoff is between $y_{t}$ and $\Delta i_{t}$ stabilization (which would be apparent in a three-dimensional figure). In contrast, the N1 and N2 rules cannot respond separately to output and inflation fluctuations, which are synchronized, therefore the only remaining tradeoff is between $y_{t}$ (or $\bar{\pi}_{t}$ ) variation and $\Delta i_{t}$ variation.

To return to the issue of model uncertainty, Table 1 and Figure 3 provide some insight into the debate about how well nominal income rules perform in various models. However, these results do not capture the model uncertainty faced by a policymaker. A policymaker must rely on a particular parameterization of a rule (with given numerical coefficients), and then consider the performance of that given rule across various models. This issue of the performance of a fixed rule across models is the essence of the model robustness criterion championed by McCallum (1998). 
A general approach to optimal robust policy is to pick the rule that does best over the set of all possible models, with each model weighted by its appropriate probability (Rudebusch 1999). As stressed by Stock (1999), the practical difficulty in applying this procedure stems from determining the probability distribution of possible models. For example, given the disparate empirical evidence reviewed in section 2 , it is difficult to summarize the likely value of $\mu_{\pi}$ other than saying it almost certainly lies in the 0.0 to 0.6 range. Still, even with such a diffuse distribution of likely values, it is possible to come to some conclusions by considering a few special cases. For example, consider the particular parameterizations of the N1, N2, and the T rules that are optimal when $\mu_{\pi}$ equals $0.0,0.3$, and 0.6 (the parameters are given in Table 1). The three panels of Figure 8 display the loss from applying these nine specific rules in a range of models with varying values of $\mu_{\pi}$. The dot on each line in the figure is placed at the value of $\mu_{\pi}$ for which the rule is optimal. For example, the results in the middle panel are relevant for the policymaker who thinks 0.3 is the most likely value for $\mu_{\pi}$ and so optimizes the policy rule for that situation. However, the policymaker must consider the performance of the rule in the event that the actual value of $\mu_{\pi}$ is not equal to 0.3 . As is apparent in the middle panel, this particular $\mathrm{T}$ rule (which is optimized for $\mu_{\pi}=0.3$ ) dominates the particular N1 and N2 rules (which are also optimized for $\mu_{\pi}=0.3$ ) at all possible values of $\mu_{\pi}$. Thus, regardless of the distribution of $\mu_{\pi}$ that is envisioned by the policymaker (e.g., normal centered at 0.3 , uniform from zero to 0.6 , etc.), this $\mathrm{T}$ rule will be preferred over the nominal output rules.

The results are much the same for the rules optimized for $\mu_{\pi}=0.0$ and $\mu_{\pi}=0.6$. For example, in the top panel of Figure 8, the policymaker chooses the optimal simple rules assuming $\mu_{\pi}=0.0$. If in fact the value of $\mu_{\pi}$ is something else, the chosen $\mathrm{T}$ rule still dominates the nominal output rules in performance. The bottom panel of Figure 8 provides an important example of the non-robustness of a policy rule. In this panel, the rules are optimized assuming that $\mu_{\pi}=0.6$. As noted in the earlier results, at $\mu_{\pi}=0.6$, the nominal income rules - and in particular the N2 rule - perform about as well as the T rule (so the three dots in the lower panel are clustered together). However, the particular parameterization of the N2 rule that is optimal at $\mu_{\pi}=0.6$ performs extremely poorly at other values of $\mu_{\pi}$. In particular, at values of $\mu_{\pi}$ less than 0.5 this N2 rule is dynamically unstable. Thus, even a policymaker who thought that $\mu_{\pi}$ was quite high would likely not choose the N2 rule because of the poor economic outcome in the case of a lower value of $\mu_{\pi}$. (Onatski, 2000, provides a fascinating extension of this work by introducing a nonparametric set of perturbations to this model and also finds that the nominal 
income rules have worse robustness characteristics.)

To summarize the results: Nominal income rules do very poorly in New Keynesian models with empirically plausible amounts of forward-looking behavior and persistence. Furthermore, from the standpoint of robustness, the N2 rule suggested by McCallum and Nelson (1999a) appears to be particularly deficient.

\section{Real-Time Output Gap Uncertainty}

In the previous section, the $\mathrm{T}$ rule was shown to perform quite well across a range of plausible model specifications. As many have noted, however, setting monetary policy on the basis of the level of the output gap, as in the Taylor rule, requires relying on a quantity that is difficult to measure accurately in real time (McCallum, 1998, Clarida, Gali, and Gertler, 2000, Smets, 1999, and Rudebusch 1999). For example, Figure 9 plots real-time estimates and final revised estimates of manufacturing capacity utilization, a measure closely related to the output gap. ${ }^{19}$ The real-time errors are clearly large in size and quite persistent; indeed, one-sided errors of a percentage point or more can extend for several quarters. As described in Rudebusch (1999) and Orphanides, et al. (1999), the real-time output gap measurement errors exhibit similar features. Accordingly, Orphanides (1999) suggests that there may be enough uncertainty in the real-time measurement of the output gap so that a nominal income rule (and specifically the N1 rule above) may out-perform the Taylor rule. This section investigates this suggestion also only considering real-time data uncertainty about the output gap. This setting puts nominal income rules in the best possible situation and provides an upper bound on their relative performance. The next section will incorporate real-time data uncertainty about inflation and other variables.

For a real-time analysis, assume that the policymaker using the $\mathrm{T}$ rule has to rely on a contemporaneous estimate of the output gap, namely, $y_{t \mid t}$. That is, the T rule (3.3) is modified to become $\mathrm{e}^{20}$

$$
i_{t}=\bar{\pi}_{t}+g_{\pi} \bar{\pi}_{t}+g_{y} y_{t \mid t}
$$

There are, of course, no published data on contemporaneous real GDP or potential output; however, in real time, the policymaker does have a large amount of information about the current-quarter state of the economy by the way of monthly, or even weekly, statistics on pro-

\footnotetext{
${ }^{19}$ In this figure, the quarterly real-time series is defined as the average of the initial release of the second month and the first revision of the first month of each quarter. These data were available in the third month of the same quarter. These data were kindly provided by Evan Koenig (1996).

${ }^{20}$ Again, assuming $r^{*}=\pi^{*}=0$.
} 
duction, employment, spending, and prices. Still, $y_{t \mid t}$ is only a very noisy contemporaneous output gap estimate, which I assume is related to the true series by

$$
y_{t \mid t}=y_{t}+n_{t}^{y}
$$

The stochastic error $n_{t}^{y}$ is the real-time measurement error plaguing the policymaker. ${ }^{21}$ It arises from errors in assessing both contemporaneous actual and potential output and has a standard error of $\sigma_{n y}$.

The variability of $n_{t}^{y}$-i.e., the size of $\sigma_{n y}$-is crucial for determining how important output gap uncertainty will be in evaluating policy rules. There are two basic modeling strategies in the literature measuring the amount of real-time uncertainty in the output gap. Each provides some important insights. One method, employed in Kuttner (1994), Smets (1999), Drew and Hunt (1999), and Tetlow (2000), uses a Kalman filter to roll through a sample of final, revised data to obtain a sequence of estimates of the model-consistent output gap. With this technique, for example, Smets (1999) estimates a $\sigma_{n y}$ of about 1.1 in the U.S. for a model with $\mu_{\pi}=0.0$. This method assumes that all of the uncertainty in the output gap comes from uncertainty about potential output and ignores both revisions to the GDP data and the real-time uncertainty about the specification of the model. ${ }^{22}$ A second method takes into account these last two uncertainties but is purely empirically based. That is, estimates of $\sigma_{n y}$, the standard deviations of the measurement error, are obtained by comparing the real-time historical estimates to the final estimates as they stand today - as in Figure 9. Notably, the analyses in Rudebusch (1999) and Orphanides, et al. (1999) suggest estimates of $\sigma_{n y}$ in the 1.0 to 2.0 percent range (depending on the exact sample and measure of resource utilization). ${ }^{23}$ Furthermore, the persistence in the output gap noise appears well-modeled by an $\operatorname{AR}(1)$ process: $n_{t}^{y}=\rho_{n y} n_{t-1}^{y}+\xi_{t}^{y}$, with estimates of $\rho_{n y}$ in the range of 0.75 to 0.95 . These two approaches provide different but quite complementary perspectives about output gap uncertainty. I use the second method to analyze the nominal income rules following the discussion in Orphanides (1999).

Table 2 gives the coefficients and volatility results for the optimal Taylor rules under various assumptions about the degree of data uncertainty. The standard deviation of the noise, $\sigma_{n y}$, is

${ }^{21}$ See Rudebusch (1999) for a discussion of the "news vs. noise" cross-correlations between the real-time estimates and the revisions and between the final estimates and the revisions.

${ }^{22}$ McCallum and Nelson (1999a) stress the model uncertainty involved in real-time output gap estimates. In their calibrated model, the true level of potential output is very different from the typical smooth representation used in most macroeconomic analysis.

${ }^{23}$ This corresponds to a 0.5 to 1.0 percentage point standard deviation for the unemployment gap, which seems reasonable given the amount of uncertainty in the estimates of the natural rate of unemployment (e.g., Staiger, Stock, and Watson, 1997). 
given the values $0,1,2$, or 3 ; as the research cited above indicates, the middle two of these cases are the most plausible. The coefficient $\rho_{n y}$ is set equal to 0.85 . Panels A, B, and C consider the three models with $\mu_{\pi}=0.0,0.3$, or 0.6 . With no output gap uncertainty $\left(\sigma_{n y}=0\right)$, the results match the T rule results in Table 1. For each model, increasing the amount of data uncertainty reduces the optimal $\mathrm{T}$ rule coefficient on the output gap and increases volatility and expected loss in an intuitive fashion. ${ }^{24}$ Most importantly, note that in Panel B (when $\mu_{\pi}=0.3$ ), even the highest loss recorded by the T rule (of 12.43 with $\sigma_{n y}=3$ ) is significantly lower than the 14.35 loss recorded for the N1 rule or the 18.04 loss recorded for the N2 rule with no data uncertainty and $\mu_{\pi}=0.3$ (in Table 1). That is, plausible or even fairly extreme, amounts of output gap uncertainty do not appear to be enough to offset the innate poor performance of the nominal income rules.

Similar results obtain in panel A with $\mu_{\pi}=0.0$, the very worst performance of the T rule (a 12.86 loss) still bests that of the N1 and N2 rules (losses of 14.34 and 16.67, respectively). In contrast, in panel $\mathrm{C}$, with $\mu_{\pi}=0.6$, the range of $\mathrm{T}$ rule results over varying amounts of output gap uncertainty brackets the nominal income rule results, with the N2 rule (with a 5.44 loss) falling at the lower end of that range and the N1 rule (with an 6.65 loss) falling at the upper end of that range. ${ }^{25}$

Still, Table 2 does not capture the full weight of uncertainty faced by a policymaker. In real time, the policymaker must choose a particular policy rule with given parameters in the face of an unknown amount of output gap measurement error. Such uncertainty about the amount of output gap measurement error is the analogue to the model uncertainty and robustness discussed above. Figure 10 provides evidence on the robustness of three such specific rule parameterizations; namely, the optimal $\mathrm{T}, \mathrm{N} 1$, and $\mathrm{N} 2$ rules assuming $\mu_{\pi}=0.3$ and, for the $\mathrm{T}$ rule, $\sigma_{n y}=2$. The expected loss values for the N1 and N2 rules in Figure 10 thus match those in panel B of Figure 8. (Again, the solid dot shows the value of $\mu_{\pi}$ for which the rule is optimized.) The solid line for the $\mathrm{T}$ rule is the loss with $\sigma_{n y}=2$, which is the value for which the policy rule has been optimized. The dotted line and the dashed lines are for that same $\mathrm{T}$ rule but with $\sigma_{n y}=3$ and $\sigma_{n y}=1$, respectively, which differ from what the policymaker assumes.

From the perspective of robustness, the $\mathrm{T}$ rule does very well, and even in the absence of

\footnotetext{
${ }^{24}$ Note that for a given model in Table 2 (i.e., for a particular panel), more output gap uncertainty results in a smaller optimal rule output coefficient. As noted in Rudebusch (1999) and Orphanides, et al. (1999), certainty equivalence does not apply because these are simple rules and the real-time gap estimates are not optimal currentquarter estimates in the context of the structural model.

${ }^{25}$ With $\mu_{\pi}=0$, this model is similar (except for the use of an ex ante real rate) to the one used by Ophanides (1999). Ophanides, however, only considers non-optimized versions of the T and N1 rules.
} 
specific probability distributions for $\mu_{\pi}$ and $\sigma_{n y}$, it is possible to make some fairly definitive comparisons. Clearly, for example, the $\mathrm{T}$ rule dominates the $\mathrm{N} 2$ rule completely across all model and data uncertainty perturbations. The N1 rule does somewhat better; still, for only a narrow set of outcomes - namely, a high $\mu_{\pi}$ of 0.5 or 0.6 and very noisy output gap measures $\left(\sigma_{n y}=3\right)$ - does the $\mathrm{N} 1$ rule surpass the $\mathrm{T}$ rule in performance.

Overall, the T rule does exceptionally well against the nominal output rules especially because only data uncertainty about the output gap has been considered.

\section{Hybrid rules}

The above results demonstrate that the $\mathrm{T}$ rule pretty clearly dominates two alternative nominal output rules that have been proposed in the literature even after consideration of likely model and output gap uncertainty. However, a policymaker need not be limited to just the discrete choice among these three simple rules. Especially with output gap uncertainty, it may be better to consider rules that augment the $\mathrm{T}$ rule response to inflation and the output gap with an additional response to nominal output growth. Specifically, consider hybrid rules of the form:

$$
i_{t}=\bar{\pi}_{t \mid t}+g_{\pi} \bar{\pi}_{t \mid t}+g_{y} y_{t \mid t}+g_{\bar{x}} \bar{x}_{t \mid t}
$$

Such a rule incorporates information on the real output gap and four-quarter nominal income growth; thus, it nests both the T and N1 rules.

Note that the hybrid rule is written to allow for real-time measurement error in all of the variables and not just the output gap. This allows for a balanced assessment of the various arguments of the rule. In order to add measurement error, it is useful to re-write the hybrid rule in another form. Specifically, splitting nominal output growth into the sum of inflation and real output growth, the hybrid rule can be re-written as

$$
i_{t}=\bar{\pi}_{t \mid t}+\left(g_{\pi}+g_{\bar{x}}\right) \bar{\pi}_{t \mid t}+g_{y} y_{t \mid t}+g_{\bar{x}} \Delta_{4} y_{t \mid t}
$$

This makes clear that the value in adding a nominal income growth response to the $\mathrm{T}$ rule is in the inclusion of a real output growth response. Federal Reserve Governor Gramlich (1999) has discussed just such a real output growth or "speed limit" modification of the Taylor rule. This modification is isomorphic to the addition of a nominal output response.

For rule (6.2), the real-time measurement errors are modeled as

$$
y_{t \mid t}=y_{t}+n_{t}^{y}, \bar{\pi}_{t \mid t}=\bar{\pi}_{t}+n_{t}^{\pi} \text {, and } \Delta_{4} y_{t \mid t}=\Delta_{4} y_{t}+n_{t}^{\Delta y}
$$


The output gap revisions, $n_{t}^{y}$, are modeled as above. The inflation revisions, $n_{t}^{\pi}$, can be obtained from the real-time and final inflation data. In the sample examined by Rudebusch (1999), the associated standard error, $\sigma_{n \bar{\pi}}$, was equal to 0.34 - much smaller than for the output gap - and the persistence of the revisions was well modeled by the third-order moving average process:

$$
n_{t}^{\pi}=\xi_{t}^{\pi}+.63 \xi_{t-1}^{\pi}+.26 \xi_{t-2}^{\pi}+.18 \xi_{t-3}^{\pi}
$$

Finally, the revisions to the four-quarter change in the output gap, $n_{t}^{\Delta y}$, appear well modeled as an $\operatorname{AR}(1)$ process $n_{t}^{\Delta y}=\rho_{n \Delta y} n_{t-1}^{\Delta y}+\xi_{t}^{\Delta y}$; however, unlike for the level of the output gap, the $n_{t}^{\Delta y}$ revisions are much smaller in size and less persistent (Orphanides, et al. 1999). I model these revisions as an $\operatorname{AR}(1)$ with $\sigma_{n \Delta y}$ equal to 0.5 or 1.0 and with $\rho_{n \Delta y}=0.5$.

The performance of the $\mathrm{T}$ rule and the hybrid rule with these three measurement error processes are examined in Table $3 .^{26}$ The three columns on the left describe the type and size of real-time data uncertainty. For all the results, the size of the output gap level uncertainty is held at $\sigma_{n y}=2$, a plausible base case. The data noise in inflation is varied with $\sigma_{n \bar{\pi}}$ equal to $0,0.3$, or 0.6 , and the data noise in the four-quarter change in the output gap is varied with $\sigma_{n \Delta y}$ equal to $0,0.5$, or 1.0. Panel A examines the performance of the pure $\mathrm{T}$ rule in this setting. The additional information in this panel beyond Table 2 is the inclusion of inflation data noise-a nonzero $\sigma_{n \bar{\pi}}$. The addition of the empirically plausible amounts of such noise reduces the optimal $\mathrm{T}$ rule inflation coefficient $\left(g_{\pi}\right)$ and adds about a tenth or two to the standard deviations of inflation and the change in the interest rate.

Panel B considers a hybrid rule that incorporates a response to the quarterly change in nominal output as suggested by the $\mathrm{N} 2$ rule (equivalently this can be viewed as the addition of the quarterly change in real output). Even with no measurement error, the quarterly change in nominal output has an optimal coefficient of essentially zero and makes almost no contribution to macroeconomic stabilization.

Finally, Panel C examines the hybrid rule with the four-quarter change in nominal output, i.e., rule (6.1) or (6.2). The addition of four-quarter output growth appears to make a perceptible, but very modest, contribution to macroeconomic stabilization. The optimal coefficient on (nominal or real) output growth $\left(g_{\bar{x}}\right)$ ranges from 0.3 to 0.5 , which suggests that the policymaker should raise the policy interest rate by 30 to 50 basis points above that suggested by a $\mathrm{T}$ rule

\footnotetext{
${ }^{26}$ I assume that the data revisions are independently distributed. It would be interesting to examine the various cross-correlations of these revisions. For example, nominal output may be measured with little error if the output gap change and inflation revisions are negatively correlated. However, the requisite sample of available Federal Reserve data has been held in confidence.
} 
when output growth is one percentage point faster than its trend or targeted amount. Such a response reduces the standard deviation of the output gap by about a tenth of a percentage point from the comparable $\mathrm{T}$ rule outcome but increases interest rate volatility (which has a smaller weight in the baseline loss function) by about the same amount. Overall, very little macroeconomic stabilization is lost by using the $\mathrm{T}$ rule instead of the hybrid rule.

\section{Conclusion}

McCallum (1998), McCallum and Nelson (1999a), Orphanides (1999), and earlier authors argue that real-time output gap uncertainty and model uncertainty (especially about the persistence of inflation) suggest that monetary policy rules that respond to nominal output growth could perform quite well. The above analysis generally supports their logic in principle but decisively rejects their arguments as persuasive for the postwar U.S. economy. The nominal output rules espoused by these authors do quite poorly over the plausible empirical range of model and data uncertainty. Furthermore, a more general rule that nests the Taylor rule and the nominal income rule suggests that output growth has little to add to optimal policy even with plausible data measurement errors.

The above analysis examines an important set of issues raised in the literature and comes to generally pessimistic conclusions regarding the performance of nominal output rules. Still, this analysis is not a definitive inquiry into the merits of nominal output rules. Obviously, the results are conditional on the simple model used, and extensions of the analysis to consider richer models with open-economy effects and more detailed or different price adjustment and aggregate demand specifications are recommended (although as noted above, as long as the monetary transmission lag from interest rates to output is significantly shorter than from interest rates to inflation, the nominal income rules (which lump the two together) will likely have difficulty stabilizing the economy). Furthermore, as stressed by McCallum (1998) and Svensson (1999b), a variety of other issues, such as the ease of policy communication and the likelihood of transparency, should also be considered in a complete assessment of policy rules.

In the context of the above loss function, however, some have suggested that the real-time information set of policymakers may be somewhat different from the one modeled above. Notably, there may be episodes of identifiable structural change during which policymakers believe that measures of the output gap are particularly uncertain. In the U.S., an examination of the output gap revisions does not readily suggest the presence of such information. However, in 
Europe, just after the start of monetary union, measures of euro-area potential output may have been particularly uncertain, so the optimal weight on the output gap relative to real or nominal output growth in a hybrid rule may be reduced. In a similar fashion, output growth may be a useful indicator for monetary policy at certain times during the business cycle: For example, while fast growth coming out of recession may have no implications for the stance of monetary policy, fast growth at cyclical booms may require policy responses. Thus, even if policymakers have only broad qualitative information about the level of the output gap, output growth may at times be a useful indicator. However, more research on the nature of time-varying optimal rule parameters and the nature of the real-time information set of policymakers is required in order to investigate such rationales. 


\section{A. Appendix: Alternative Forward-Looking Output Equation}

This appendix provides an alternative set of results using an output equation that is modified to incorporate explicitly forward-looking output expectations. As noted in Section 2, such a specification, which is based on the standard Euler equation for household behavior in which current consumption depends on future consumption and the real rate, qualifies better as new Keynesian in spirit. However, the standard Euler equation with forward-looking behavior displays a severe lack of empirical fit as shown in Estrella and Fuhrer (1998). Indeed, one of the few (and perhaps the only) available empirical estimates of the weight on explicit future output expectations in the output equation is provided in Fuhrer (2000). He estimates a model of consumption that augments the usual consumption Euler equation with both "habit formation" and "rule-of-thumb" behavior. McCallum and Nelson (1999) provide a linearized version of the first order conditions of this model with only habit formation (their equation 34), which can be re-written with Fuhrer's parameter estimates as

$$
c_{t}=.323 c_{t-1}+.677 E_{t} c_{t+1}-.017 r_{t}+\eta_{t},
$$

where $c_{t}$ is (following Fuhrer) the log of per capita detrended nondurable goods and services consumption and $r_{t}$ is an ex ante real rate. ${ }^{27}$ These empirical estimates suggest that consumers place about a two-thirds weight on future consumption in determining current consumption. However, it is important to note that in order to fit an empirical model of total real output, Fuhrer (2000) uses equation (A.1) to explain only about half of real output. There are two restriction on its coverage. First, in order to fit the model, Fuhrer estimates that this Euler equation only applies to about 74 percent of nondurables and services consumption with the remaining fraction of consumption determined by the rule of thumb, $c_{t}=y_{t}$. Second, he uses a completely autoregressive model to fit the non-consumption portion of real output, which averages about 41 percent of the total over the sample. Thus, taking into account these various fractions, Fuhrer's model of total real output — as estimated — has about a one-third weight on explicit expectations of future output. In order to approximate this weight on the future, I generalize the model of model of section 2 as

$$
y_{t}=\mu_{y} E_{t-1} y_{t+1}+\left(1-\mu_{y}\right)\left(\beta_{y 1} y_{t-1}+\beta_{y 2} y_{t-2}\right)-\beta_{r}\left(\imath_{t-1}-E_{t-1} \bar{\pi}_{t+3}\right)+\eta_{t},
$$

${ }^{27}$ The coefficient shown for $E_{t} c_{t+1}$ is actually the sum of the coefficients on $E_{t} c_{t+1}$ and $E_{t} c_{t+2}$ (namely 0.997 plus -0.320), which I collapse together to eliminate extraneous dynamics that have no effect on the results. 
and set $\mu_{y}=0.3$ while the other parameters retain their previous values. ${ }^{28}$

Tables A1 and A2 provide the equivalent results to Tables 1 and 2 in the text for the model with an output equation with $\mu_{y}=0.3$. As shown in Table A1, the T rule still dominates the $\mathrm{N} 1$ and N2 rules for $\mu_{\pi}=0.0,0.3$, or 0.6 and $\mu_{y}=0.3$. Furthermore, as shown in Table A2, with little exception, the $\mathrm{T}$ rule continues to dominate even after significant output gap noise is incorporated into the analysis.

\footnotetext{
${ }^{28}$ Even worse results for the nominal income growth rules were obtained with other forward-looking output equations, including using equation (A.1) directly for all of real output with $y_{t}$ in place of $c_{t}$.
} 
Table 1

Results for Three Optimized Simple Rules

\begin{tabular}{|c|c|c|c|c|}
\hline \multirow[b]{2}{*}{ Rule } & \multicolumn{3}{|c|}{ Volatility Results } & \multirow{2}{*}{$\begin{array}{c}\text { Expected } \\
\text { Loss }\end{array}$} \\
\hline & $\operatorname{Std}\left[\bar{\pi}_{t}\right]$ & $\operatorname{Std}\left[y_{t}\right]$ & $\operatorname{Std}\left[\Delta i_{t}\right]$ & \\
\hline \multicolumn{5}{|c|}{ Panel A. Model with $\mu_{\pi}=0.0$} \\
\hline $\mathrm{T}\left(g_{\pi}=2.06, g_{y}=1.55\right)$ & 1.98 & 2.07 & 1.75 & 9.76 \\
\hline $\mathrm{N} 1\left(g_{x}=1.10\right)$ & 2.61 & 2.50 & 1.61 & 14.34 \\
\hline $\mathrm{N} 2\left(g_{x}=0.57, \rho=0.72\right)$ & 2.90 & 2.37 & 2.28 & 16.67 \\
\hline \multicolumn{5}{|c|}{ Panel B. Model with $\mu_{\pi}=0.3$} \\
\hline $\mathrm{T}\left(g_{\pi}=1.86, g_{y}=1.74\right)$ & 1.62 & 1.78 & 1.87 & 7.54 \\
\hline $\mathrm{N} 1\left(g_{x}=1.52\right)$ & 2.51 & 2.38 & 2.20 & 14.35 \\
\hline $\mathrm{N} 2\left(g_{x}=0.77, \rho=0.68\right)$ & 2.87 & 2.24 & 3.08 & 18.04 \\
\hline \multicolumn{5}{|c|}{ Panel C. Model with $\mu_{\pi}=0.6$} \\
\hline $\mathrm{T}\left(g_{\pi}=0.88, g_{y}=1.55\right)$ & 1.09 & 1.55 & 1.59 & 4.86 \\
\hline $\mathrm{N} 1\left(g_{x}=1.25\right)$ & 1.47 & 1.70 & 1.78 & 6.65 \\
\hline $\mathrm{N} 2\left(g_{x}=0.43, \rho=0.95\right)$ & 1.19 & 1.63 & 1.65 & 5.44 \\
\hline
\end{tabular}


Table 2

Optimal Taylor Rule Results with Output Gap Uncertainty

\begin{tabular}{|c|c|c|c|c|c|c|}
\hline \multirow{2}{*}{$\frac{y_{t \mid t} \text { Noise }}{\sigma_{n y}}$} & \multicolumn{2}{|c|}{ Rule Parameters } & \multicolumn{3}{|c|}{ Volatility Results } & \multirow{2}{*}{$\begin{array}{c}\text { Expected } \\
\text { Loss }\end{array}$} \\
\hline & $g_{\pi}$ & $g_{y}$ & $\operatorname{Std}\left[\bar{\pi}_{t}\right]$ & $\operatorname{Std}\left[y_{t}\right]$ & $\operatorname{Std}\left[\Delta i_{t}\right]$ & \\
\hline \multicolumn{7}{|c|}{ Panel A. Model with $\mu_{\pi}=0$} \\
\hline 0.0 & 2.06 & 1.55 & 1.98 & 2.07 & 1.75 & 9.76 \\
\hline 1.0 & 1.92 & 1.26 & 2.04 & 2.21 & 1.70 & 10.48 \\
\hline 2.0 & 1.69 & 0.82 & 2.15 & 2.44 & 1.55 & 11.77 \\
\hline 3.0 & 1.49 & 0.51 & 2.26 & 2.62 & 1.37 & 12.86 \\
\hline \multicolumn{7}{|c|}{ Panel B. Model with $\mu_{\pi}=0.3$} \\
\hline 0.0 & 1.86 & 1.74 & 1.62 & 1.78 & 1.87 & 7.54 \\
\hline 1.0 & 1.86 & 1.43 & 1.72 & 1.97 & 1.88 & 8.59 \\
\hline 2.0 & 1.80 & 0.98 & 1.91 & 2.28 & 1.85 & 10.56 \\
\hline 3.0 & 1.70 & 0.66 & 2.10 & 2.54 & 1.77 & 12.43 \\
\hline \multicolumn{7}{|c|}{ Panel C. Model with $\mu_{\pi}=0.6$} \\
\hline 0.0 & 0.88 & 1.55 & 1.09 & 1.55 & 1.59 & 4.86 \\
\hline 1.0 & 1.23 & 1.12 & 1.19 & 1.73 & 1.59 & 5.65 \\
\hline 2.0 & 1.46 & 0.65 & 1.29 & 1.94 & 1.56 & 6.62 \\
\hline 3.0 & 1.55 & 0.38 & 1.35 & 2.06 & 1.52 & 7.22 \\
\hline
\end{tabular}


Table 3

Optimal Hybrid Rule Results with Real-Time Data Uncertainty

\begin{tabular}{|c|c|c|c|c|c|c|c|c|c|}
\hline \multicolumn{3}{|c|}{ Data Noise } & \multicolumn{3}{|c|}{ Rule Parameters } & \multicolumn{3}{|c|}{ Volatility Results } & \multirow{2}{*}{$\begin{array}{c}\text { Expected } \\
\text { Loss }\end{array}$} \\
\hline$\sigma_{n y}$ & $\sigma_{n \bar{\pi}}$ & $\sigma_{n \Delta y}$ & $g_{\pi}$ & $g_{y}$ & $g_{x}$ or $g_{\bar{x}}$ & $\operatorname{Std}\left[\bar{\pi}_{t}\right]$ & $\operatorname{Std}\left[y_{t}\right]$ & $\operatorname{Std}\left[\Delta i_{t}\right]$ & \\
\hline \multicolumn{10}{|c|}{ Panel A. Rule: $i_{t}=\bar{\pi}_{t \mid t}+g_{\pi} \bar{\pi}_{t \mid t}+g_{y} y_{t \mid t}$} \\
\hline 2.0 & 0.0 & 0.0 & 1.80 & 0.98 & - & 1.91 & 2.28 & 1.85 & 10.56 \\
\hline 2.0 & 0.3 & 0.0 & 1.67 & 0.96 & - & 1.98 & 2.27 & 1.96 & 11.01 \\
\hline 2.0 & 0.6 & 0.0 & 1.42 & 0.92 & - & 2.14 & 2.27 & 2.21 & 12.17 \\
\hline \multicolumn{10}{|c|}{ Panel B. Rule: $i_{t}=\bar{\pi}_{t \mid t}+g_{\pi} \bar{\pi}_{t \mid t}+g_{y} y_{t \mid t}+g_{x} x_{t \mid t}$} \\
\hline 2.0 & 0.0 & 0.0 & 1.76 & 0.95 & 0.04 & 1.91 & 2.26 & 1.88 & 10.54 \\
\hline \multicolumn{10}{|c|}{ Panel C. Rule: $i_{t}=\bar{\pi}_{t \mid t}+g_{\pi} \bar{\pi}_{t \mid t}+g_{y} y_{t \mid t}+g_{\bar{x}} \bar{x}_{t \mid t}$} \\
\hline 2.0 & 0.0 & 0.0 & 1.43 & 0.82 & 0.52 & 1.87 & 2.17 & 1.95 & 10.10 \\
\hline 2.0 & 0.3 & 0.0 & 1.28 & 0.81 & 0.49 & 1.95 & 2.16 & 2.06 & 10.59 \\
\hline 2.0 & 0.3 & 0.5 & 1.32 & 0.82 & 0.44 & 1.95 & 2.17 & 2.05 & 10.62 \\
\hline 2.0 & 0.3 & 1.0 & 1.40 & 0.85 & 0.34 & 1.95 & 2.20 & 2.04 & 10.71 \\
\hline 2.0 & 0.6 & 0.0 & 1.03 & 0.79 & 0.44 & 2.12 & 2.16 & 2.30 & 11.82 \\
\hline 2.0 & 0.6 & 0.5 & 1.07 & 0.80 & 0.40 & 2.12 & 2.17 & 2.30 & 11.85 \\
\hline 2.0 & 0.6 & 1.0 & 1.15 & 0.82 & 0.31 & 2.12 & 2.19 & 2.28 & 11.92 \\
\hline
\end{tabular}


Table A1

Results for Three Optimized Simple Rules

\begin{tabular}{|c|c|c|c|c|}
\hline \multirow[b]{2}{*}{ Rule } & \multicolumn{3}{|c|}{ Volatility Results } & \multirow{2}{*}{$\begin{array}{c}\text { Expected } \\
\text { Loss }\end{array}$} \\
\hline & $\operatorname{Std}\left[\bar{\pi}_{t}\right]$ & $\operatorname{Std}\left[y_{t}\right]$ & $\operatorname{Std}\left[\Delta i_{t}\right]$ & \\
\hline \multicolumn{5}{|c|}{ Panel A. Model with $\mu_{\pi}=0.0$ and $\mu_{y}=0.3$} \\
\hline $\mathrm{T}\left(g_{\pi}=1.45, g_{y}=1.01\right)$ & 1.78 & 1.90 & 1.23 & 7.51 \\
\hline $\mathrm{N} 1\left(g_{x}=0.66\right)$ & 2.16 & 2.12 & 1.03 & 9.68 \\
\hline $\mathrm{N} 2\left(g_{x}=0.47, \rho=0.71\right)$ & 2.60 & 2.06 & 1.94 & 13.00 \\
\hline \multicolumn{5}{|c|}{ Panel B. Model with $\mu_{\pi}=0.3$ and $\mu_{y}=0.3$} \\
\hline $\mathrm{T}\left(g_{\pi}=1.23, g_{y}=1.06\right)$ & 1.36 & 1.58 & 1.22 & 5.12 \\
\hline $\mathrm{N} 1\left(g_{x}=0.79\right)$ & 1.86 & 2.02 & 1.19 & 8.23 \\
\hline $\mathrm{N} 2\left(g_{x}=0.60, \rho=0.67\right)$ & 2.42 & 1.98 & 2.53 & 13.01 \\
\hline \multicolumn{5}{|c|}{ Panel C. Model with $\mu_{\pi}=0.6$ and $\mu_{y}=0.3$} \\
\hline $\mathrm{T}\left(g_{\pi}=0.36, g_{y}=0.94\right)$ & 0.90 & 1.31 & 0.98 & 3.01 \\
\hline $\mathrm{N} 1\left(g_{x}=0.65\right)$ & 1.01 & 1.50 & 1.01 & 3.77 \\
\hline $\mathrm{N} 2\left(g_{x}=0.27, \rho=0.96\right)$ & 0.98 & 1.40 & 1.04 & 3.47 \\
\hline
\end{tabular}


Table A2

\section{Optimal Taylor Rule Results with Output Gap Uncertainty}

\begin{tabular}{|c|c|c|c|c|c|c|}
\hline \multirow{2}{*}{$\frac{y_{t \mid t} \text { Noise }}{\sigma_{n y}}$} & \multicolumn{2}{|c|}{ Rule Parameters } & \multicolumn{3}{|c|}{ Volatility Results } & \multirow{2}{*}{$\begin{array}{c}\text { Expected } \\
\text { Loss }\end{array}$} \\
\hline & $g_{\pi}$ & $g_{y}$ & $\operatorname{Std}\left[\bar{\pi}_{t}\right]$ & $\operatorname{Std}\left[y_{t}\right]$ & $\operatorname{Std}\left[\Delta i_{t}\right]$ & \\
\hline \multicolumn{7}{|c|}{ Panel A. Model with $\mu_{\pi}=0.0$ and $\mu_{y}=0.3$} \\
\hline 0.0 & 1.45 & 1.01 & 1.78 & 1.90 & 1.23 & 7.51 \\
\hline 1.0 & 1.29 & .77 & 1.80 & 2.01 & 1.14 & 7.95 \\
\hline 2.0 & 1.03 & .42 & 1.86 & 2.18 & 0.95 & 8.64 \\
\hline 3.0 & .86 & .21 & 1.91 & 2.27 & .81 & 9.10 \\
\hline \multicolumn{7}{|c|}{ Panel B. Model with $\mu_{\pi}=0.3$ and $\mu_{y}=0.3$} \\
\hline 0.0 & 1.23 & 1.06 & 1.36 & 1.58 & 1.22 & 5.12 \\
\hline 1.0 & 1.18 & .81 & 1.40 & 1.74 & 1.17 & 5.68 \\
\hline 2.0 & 1.04 & .47 & 1.47 & 2.00 & 1.05 & 6.23 \\
\hline 3.0 & .89 & .26 & 1.53 & 2.14 & .93 & 7.35 \\
\hline \multicolumn{7}{|c|}{ Panel C. Model with $\mu_{\pi}=0.6$ and $\mu_{y}=0.3$} \\
\hline 0.0 & .36 & .94 & .90 & 1.31 & .98 & 3.01 \\
\hline 1.0 & .59 & .63 & .93 & 1.48 & .92 & 3.47 \\
\hline 2.0 & .61 & .31 & .96 & 1.65 & .82 & 3.96 \\
\hline 3.0 & .57 & .16 & .97 & 1.73 & .75 & 4.21 \\
\hline
\end{tabular}




\section{References}

[1] Anderson, Gary S., and George Moore (1985). "A Linear Algebraic Procedure for Solving Linear Perfect Foresight Models," Economics Letters, vol. 17, pp. 247-52.

[2] Andrews, Donald W.K. (1993). "Tests for Parameter Instability and Structural Change with Unknown Change Point," Econometrica, vol. 61(4), pp. 821-856.

[3] Ball, Laurence (1999). "Efficient Rules for Monetary Policy," International Finance, vol. 2(1), pp. 63-83.

[4] Bank of England (1999). Economic Models at the Bank of England, London.

[5] Brayton, Flint, Andrew Levin, Ralph Tryon, and John C. Williams (1997). "The Evolution of Macro Models at the Federal Reserve Board," Carnegie-Rochester Conference Series on Public Policy, vol. 47, pp. 43-81.

[6] Brayton, Flint, John Roberts, and John C. Williams (1999). "What's Happened to the Phillips Curve?," FEDS Working Paper No. 1999-49, Federal Reserve Board, Washington, DC.

[7] Calvo, G. (1983), "Staggered Prices in a Utility-Maximizing Framework," Journal of Monetary Economics, vol.12, pp. 383-98.

[8] Chadha, Bankim, Paul R. Masson, and Guy Meredith (1992). "Models of Inflation and the Costs of Disinflation," IMF Staff Papers, vol. 39, pp. 395-431.

[9] Clarida, Richard, Jordi Gali, and Mark Gertler (2000). "Monetary Policy Rules and Macroeconomic Stability: Evidence and Some Theory," Quarterly Journal of Economics, vol. 115, pp. 147-180.

[10] Clark, Peter, Douglas Laxton, and David Rose (1996). "Asymmetry in the U.S. OutputInflation Nexus," IMF Staff Papers, vol. 43, pp. 216-251.

[11] Congressional Budget Office (1995). "CBO's Method for Estimating Potential Output," CBO Memorandum (October).

[12] Dennis, Richard (1999a). "Inflation Expectations and the Stability Properties of Nominal GDP Targeting," manuscript, Australian National University. 
[13] Dennis, Richard (1999b). "On Efficiency and Taylor Type Rules," manuscript, Australian National University.

[14] Drew, Aaron, and Benjamin Hunt (1999). "The Effects of Potential Output Uncertainty on the Performance of Simple Policy Rules," in Benjamin Hunt and Adrian Orr (eds.), Monetary Policy Under Uncertainty, Wellington, New Zealand: Reserve Bank of New Zealand, pp. 173-102.

[15] Diebold, Francis X., and Glenn D. Rudebusch (1991). "Forecasting Output With the Composite Leading Index: A Real-Time Analysis," Journal of the American Statistical Association, vol.86, pp. 603-610.

[16] Estrella, Arturo, and Jeffrey C. Fuhrer (1998). "Dynamic Inconsistencies: Counterfactual Implications of a Class of Rational Expectations Models," Working Paper No. 98-5, Federal Reserve Bank of Boston.

[17] European Central Bank (1999). "Euro Area Monetary Aggregates and Their Role in the Eurosystem's Monetary Policy Strategy," ECB Monthly Bulletin, February 1999, pp. 29-40.

[18] Fair, Ray C. (1993). "Testing the Rational Expectations Hypothesis in Macroeconometric Models," Oxford Economic Papers, vol. 45, pp. 169-190.

[19] Feldstein, Martin, and James H. Stock (1994). "The Use of a Monetary Aggregate to Target Nominal GDP," in Monetary Policy, ed. by N. Gregory Mankiw, Chicago University Press, pp. 7-62.

[20] Fuhrer, Jeffrey C. (1997). “The (Un)Importance of Forward-Looking Behavior in Price Specifications," Journal of Money, Credit, and Banking (August), pp. 338-350.

[21] Fuhrer, Jeffrey C. (2000). "Habit Formation in Consumption and its Implications for Monetary-Policy Models," The American Economic Review, vol. 90(3), pp. 367-90.

[22] Fuhrer, Jeffery C., and George R. Moore (1995). "Inflation Persistence," Quarterly Journal of Economics, vol. 110, pp. 127-60.

[23] Gali, Jordi, and Mark Gertler (1999). "Inflation Dynamics: A Structural Econometric Analysis," Journal of Monetary Economics, vol. 44, pp. 195-222. 
[24] Goodfriend, Marvin, and Robert G. King (1997). "The New Neoclassical Synthesis and the Role of Monetary Policy," in NBER Macroeconomics Annual 1997, pp. 231-283.

[25] Gordon, Robert (1985). "The Conduct of Domestic Monetary Policy," in Monetary Policy in Our Times, ed. by A. Ando et al., MIT press, pp. 45-81.

[26] Gruen, David, Adrian Pagan, and Christopher Thompson (1999). "The Phillips Curve in Australia," Journal of Monetary Economics, vol. 44(2), pp. 223-58.

[27] Gramlich, Edward M., (1999). "A Stabilization Policy Strategy," Speech before the Wharton Public Policy Forum Series, Philadelphia, Pennsylvania, (April 22). Available at $<$ www.federalreserve.gov/s-t.htm >

[28] Hall, Robert, and N. Gregory Mankiw (1994). "Nominal Income Targeting," in Monetary Policy, ed. by N. Gregory Mankiw, Chicago University Press, pp. 71-93.

[29] Jensen, Henrik (1999). "Targeting Nominal Income Growth or Inflation?," manuscript, University of Copenhagen.

[30] Judd, John P., and Brian Motley (1992). "Controlling Inflation with an Interest Rate Instrument," Economic Review, Federal Reserve Bank of San Francisco, no. 3, pp. 3-22.

[31] Koenig, Evan (1996). "Capacity Utilization As a Real-Time Predictor of Manufacturing Output," Economic Review (Third Quarter), Federal Reserve Bank of Dallas, pp. 16-23.

[32] Kuttner, Ken (1994). "Estimating Potential Output as a Latent Variable," Journal of Business and Economic Statistics, vol. 12, pp. 361-368.

[33] Laxton, D., P. Isard, H. Faruqee, E. Prasad, and B. Turtelboom (1998). "Multimod Mark III: The Core Dynamic and Steady-State Models," Occasional paper 164, International Monetary Fund, Washington DC.

[34] Levin, Andrew, Volker Wieland, and John C. Williams (1999). "Robustness of Simple Monetary Policy Rules under Model Uncertainty," in Monetary Policy Rules, ed. by John B. Taylor, Chicago: Chicago University Press, pp. 263-299.

[35] Maclean, Dinah (1998). "Incorporating Credibility in Forward-Looking Models: Some Examples with QPM," in Topics in Monetary Policy Modelling, Bank for International Settlements, Conference Papers, vol. 6, pp. 112-149. 
[36] McCallum, Bennett T. (1988). "Robustness Properties of a Rule for Monetary Policy," Carnegie-Rochester Conference Series on Public Policy, vol. 29, pp.173-204.

[37] McCallum, Bennett T. (1997). "The Alleged Instability of Nominal Income Targeting," NBER Working Paper No. 6291.

[38] McCallum, Bennett T. (1998). "Issues in the Design of Monetary Policy Rules," in John B. Taylor and Michael Woodford (eds.), Handbook of Macroeconomics (North-Holland), pp. 1483-1530.

[39] McCallum, Bennett T. and Edward Nelson (1999a). "Performance of Operational Policy Rules in an Estimated Semiclassical Structural Model," in Monetary Policy Rules, ed. by John B. Taylor, pp. 15-54. Chicago: Chicago University Press.

[40] McCallum, Bennett T. and Edward Nelson (1999b). "Nominal Income Targeting in an Open-Economy Optimizing Model," Journal of Monetary Economics, vol. 43, pp. 553-578.

[41] Orphanides, Athanasios (1999). "The Quest for Prosperity Without Inflation," manuscript, Federal Reserve Board.

[42] Orphanides, Athanasios, Richard Porter, David Reifschneider, Robert Tetlow, and Frederico Finan (1999). "Errors in the Measurement of the Output Gap and the Design of Monetary Policy," Journal of Economics and Business, vol. 52, pp. 117-42.

[43] Onatski, Alexei (2000). "Minimax Analysis of Policy Rules Under Model Uncertainty," manuscript, Harvard University, Boston.

[44] Reifschneider, David, and John C. Williams (1999). "Three Lessons for Monetary Policy in a Low Inflation Era," Finance and Economics Discussion Series 1999-44, Federal Reserve Board, Washington DC.

[45] Roberts, John M. (1995). "New Keynesian Economics and the Phillips Curve," Journal of Money and Banking (November), pp. 975-984.

[46] Roberts, John M. (1998). "Inflation Expectations and the Transmission of Monetary Policy," Finance and Economics Discussion Series 1998-43, Federal Reserve Board, Washington DC. 
[47] Roberts, John M. (1999). "How Well Does the New Keynesian Sticky-Price Model Fit the Data?," manuscript, Federal Reserve Board, Washington DC.

[48] Rotemberg, Julio (1982). "Sticky Prices in the United States," Journal of Political Economy, vol. 60, pp. 1187-1211.

[49] Rotemberg, Julio, and Michael Woodford (1999). "Interest Rate Rules in an Estimated Sticky Price Model," in Monetary Policy Rules, ed. by John B. Taylor, Chicago: Chicago University Press, pp. 57-119.

[50] Rudebusch, Glenn D. (1998). "Do Measures of Monetary Policy in a VAR Make Sense?," International Economic Review, vol. 39(4), pp. 907-931.

[51] Rudebusch, Glenn D. (1999). "Is the Fed Too Timid? Monetary Policy in an Uncertain World," Working Paper 99-05, Federal Reserve Bank of San Francisco, forthcoming in the Review of Economics and Statistics.

[52] Rudebusch, Glenn D. (2000). "Term Structure Evidence on Interest Rate Smoothing and Monetary Policy Inertia," manuscript, Federal Reserve Bank of San Francisco.

[53] Rudebusch, Glenn D., and Lars E.O. Svensson (1999). "Policy Rules for Inflation Targeting," in Monetary Policy Rules, ed. by John B. Taylor, Chicago: Chicago University Press, pp. 203-246.

[54] Rudebusch, Glenn D., and Lars E.O. Svensson (2000). "Eurosystem Monetary Targeting: Lessons from U.S. Data," manuscript, Federal Reserve Bank of San Francisco.

[55] Sbordone, Argia (1998). "Prices and Unit Labor Costs: A New Test of Price Stickiness," manuscript, Rutgers University.

[56] Smets, Frank (1999). "Output Gap Uncertainty: Does It Matter for the Taylor Rule?," in Benjamin Hunt and Adrian Orr (eds.), Monetary Policy Under Uncertainty, Wellington, New Zealand: Reserve Bank of New Zealand, pp. 10-29.

[57] Smets, Frank (2000). "What Horizon for Price Stability?," manuscript, European Central Bank.

[58] Staiger, Douglas, James H. Stock, and Mark W. Watson (1997). "The NAIRU, Unemployment, and Monetary Policy," Journal of Economic Perspectives, vol. 11, pp. 33-49. 
[59] Stock, James H. (1999). "Comment," in Monetary Policy Rules, ed. by John B. Taylor, Chicago: Chicago University Press, pp. 253-259.

[60] Svensson, Lars E.O. (1999a). "Inflation Targeting: Some Extensions," Scandinavian Journal of Economics vol. 101, pp. 337-361.

[61] Svensson, Lars E.O. (1999b). "Inflation Targeting as a Monetary Policy Rule," Journal of Monetary Economics, vol. 43, pp. 607-654.

[62] Taylor, John B. (1980). “Aggregate Dynamics and Staggered Contracts," Journal of Political Economy, vol. 88, pp. 1-23.

[63] Taylor, John B. (1985). "What Would Nominal GNP Targeting Do to the Business Cycle?," Carnegie-Rochester Conference Series on Public Policy, vol. 22, pp. 61-68.

[64] Taylor, John B. (1993). "Discretion versus Policy Rules in Practice," Carnegie-Rochester Conference Series on Public Policy, vol. 39, pp. 195-214.

[65] Taylor, John B.(1999). "An Historical Analysis of Monetary Policy Rules," in John B. Taylor (ed.), Monetary Policy Rules, Chicago, IL: Chicago University Press, 319-341.

[66] Tetlow, Robert (2000). "Uncertain Potential Output and Monetary Policy in a ForwardLooking Model," manuscript, Federal Reserve Board, Washington, DC.

[67] Trehan, Bharat (1999). "Supply Shocks and the Conduct of Monetary Policy," Economic Letter (July), pp. 99-21, Federal Reserve Bank of San Francisco.

[68] Walsh, Carl E. (1998). Monetary Theory and Policy, Cambridge MA: MIT Press.

[69] Williams, John C. (1999). "Simple Rules for Monetary Policy," Finance and Economics Discussion Series 1999-12, Federal Reserve Board, Washington DC.

[70] Woodford, Michael (1996). "Control of the Public Debt: A Requirement for Price Stability?," NBER Working Paper No. 5984.

[71] Woodford, Michael (1999). "Optimal Monetary Policy Inertia," The Manchester School Supplement, pp. 1-35. 


\section{Figure 1}

\section{Impulse Responses for VAR and Structural Model (with $\mu_{\pi}=\mathbf{0 . 3}$ )}
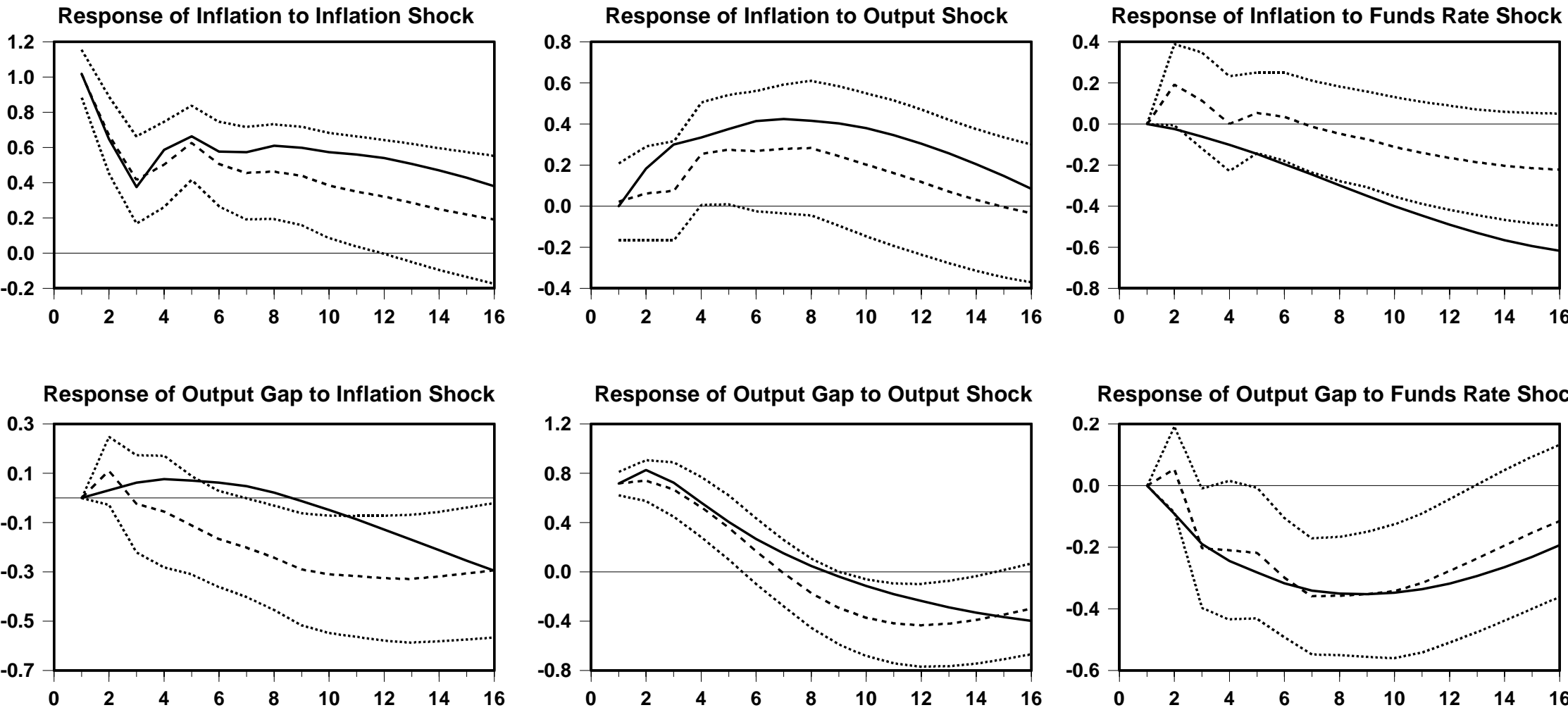

Response of Output Gap to Output Shock

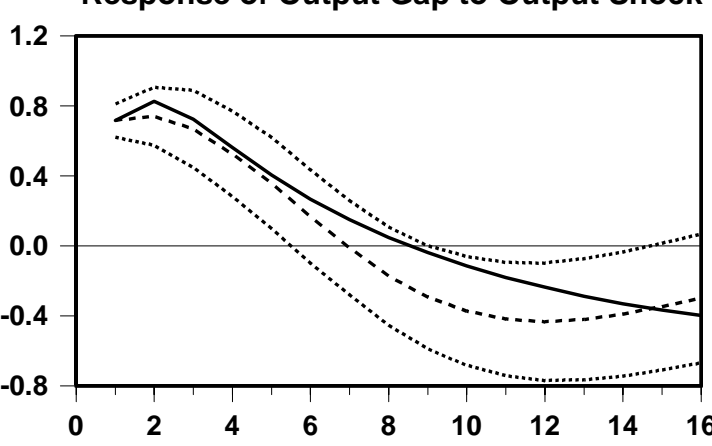

Response of Output Gap to Funds Rate Shock

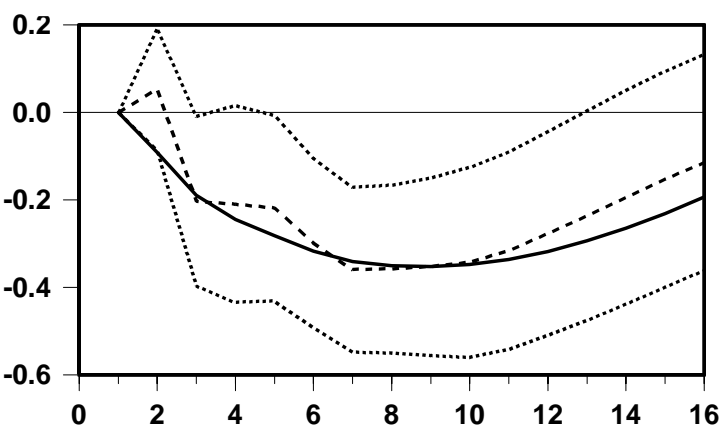

Response of Funds Rate to Inflation Shock

Response of Funds Rate to Output Shock
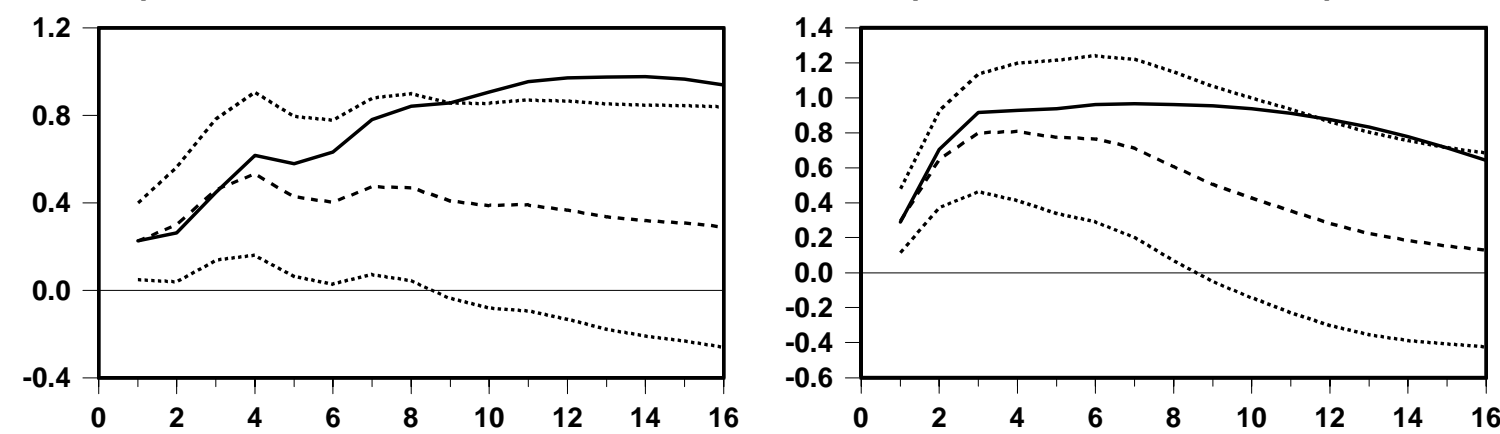

Response of Funds Rate to Funds Rate Shock

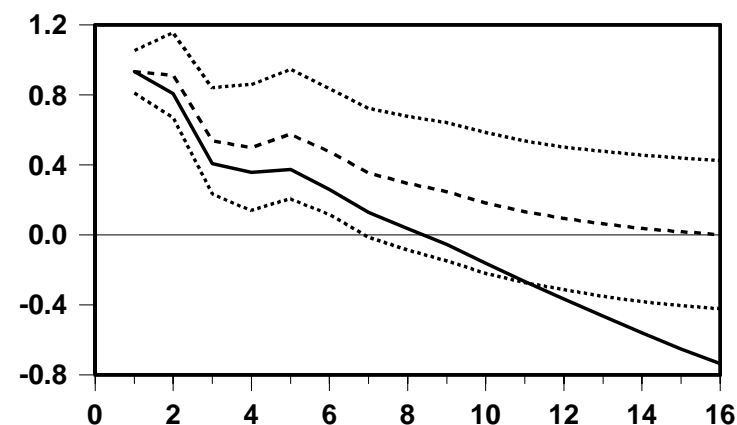




\section{Figure 2}

\section{Impulse Responses for VAR and Structural Model (with $\mu_{\pi}=\mathbf{0 . 8}$ )}
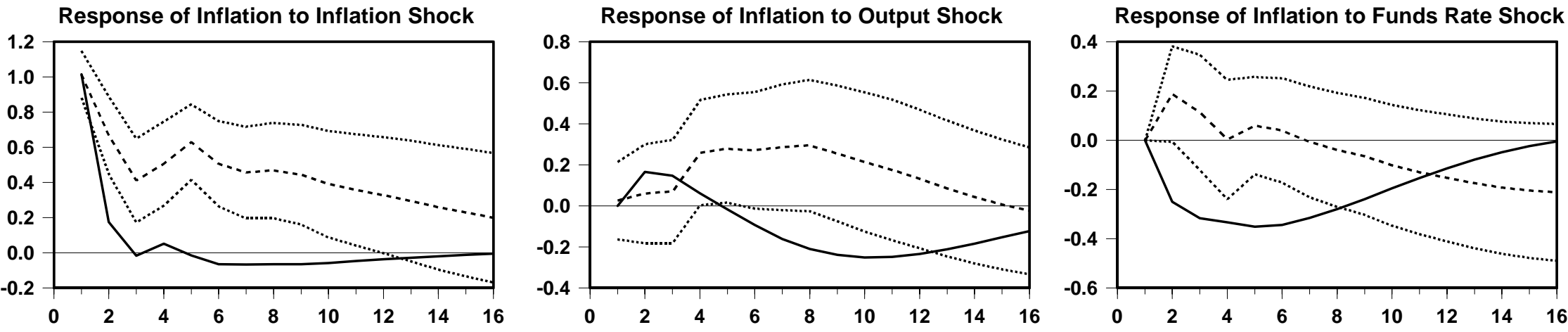

Response of Output Gap to Inflation Shock

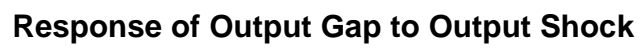

Response of Output Gap to Funds Rate Shock
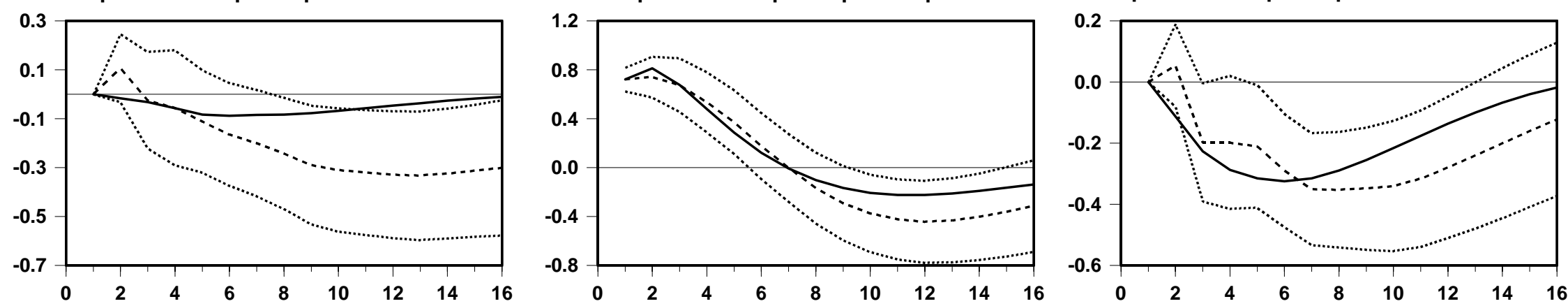

Response of Funds Rate to Inflation Shock

Response of Funds Rate to Output Shock

Response of Funds Rate to Funds Rate Shock
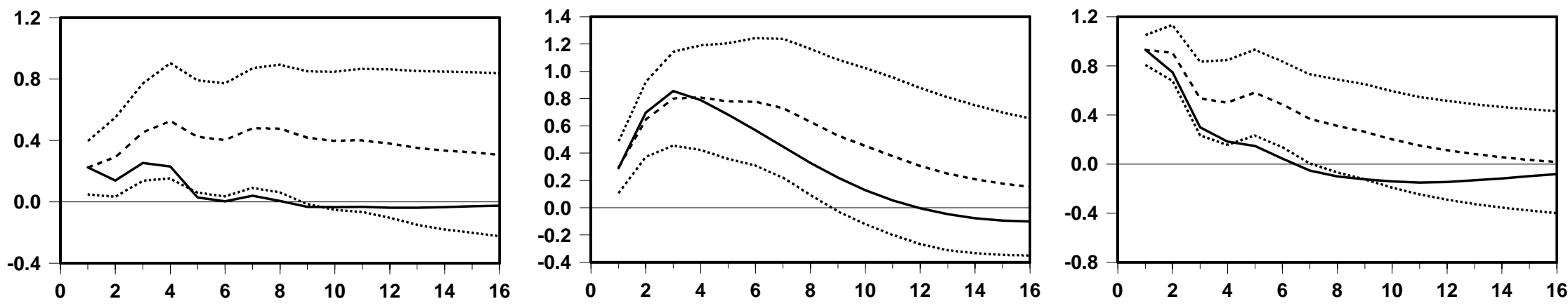
Figure 3

\section{Expected Loss From Three Optimized Simple Rules}

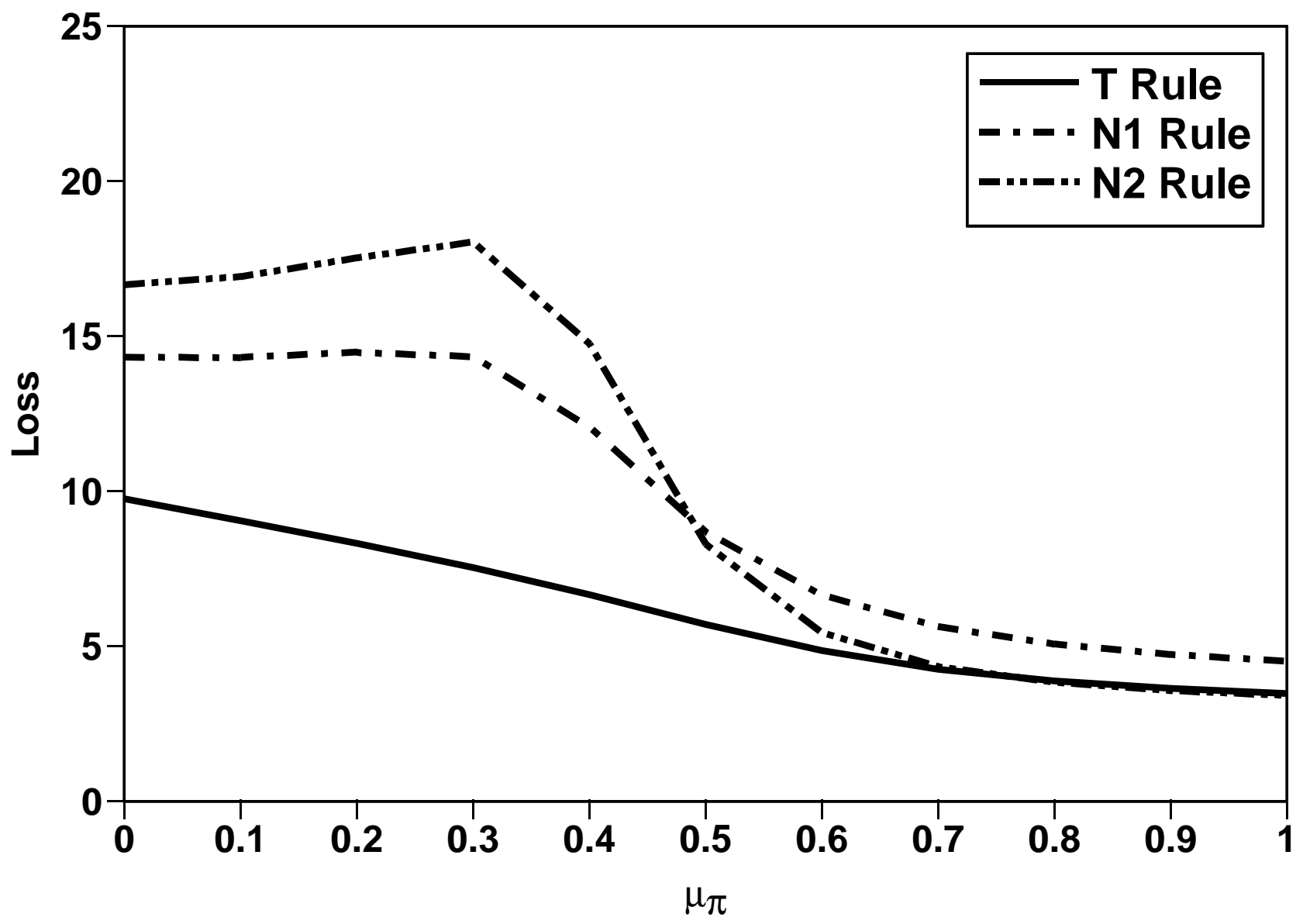


Figure 4

Impulse Responses for Model with $\mu_{\pi}=\mathbf{0 . 3}$

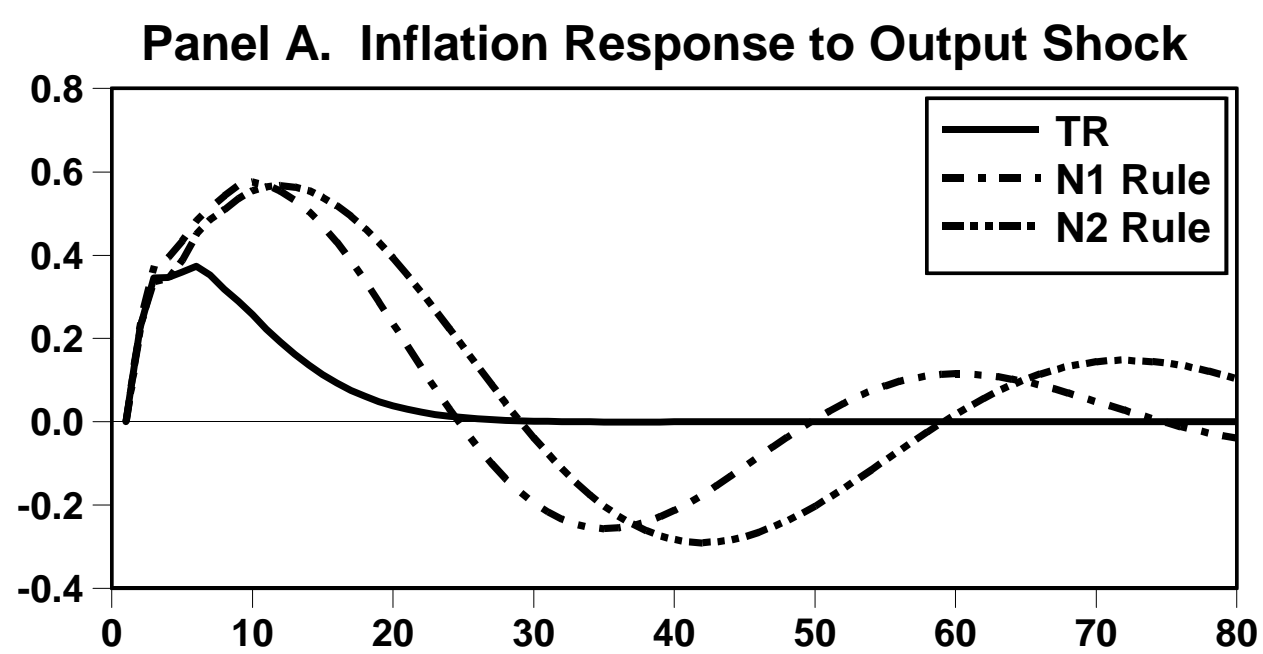

Panel B. Output Response to Output Shock

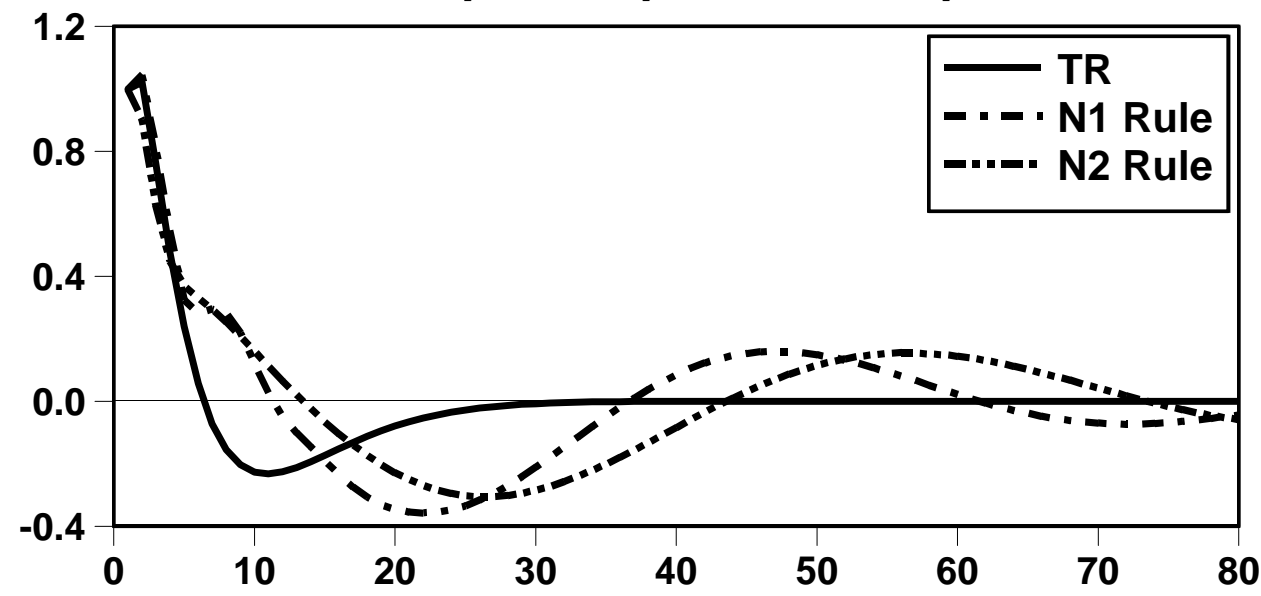

Panel C. Funds Rate Response to Output Shock

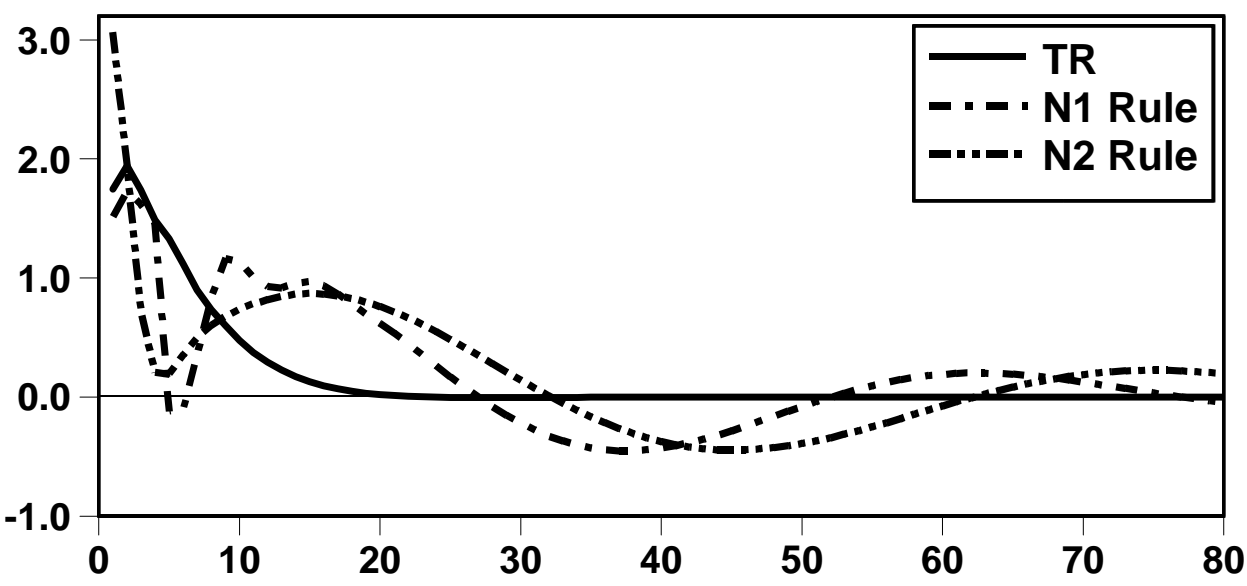


Figure 5

Impulse Responses for Model with $\mu_{\pi}=\mathbf{0 . 8}$
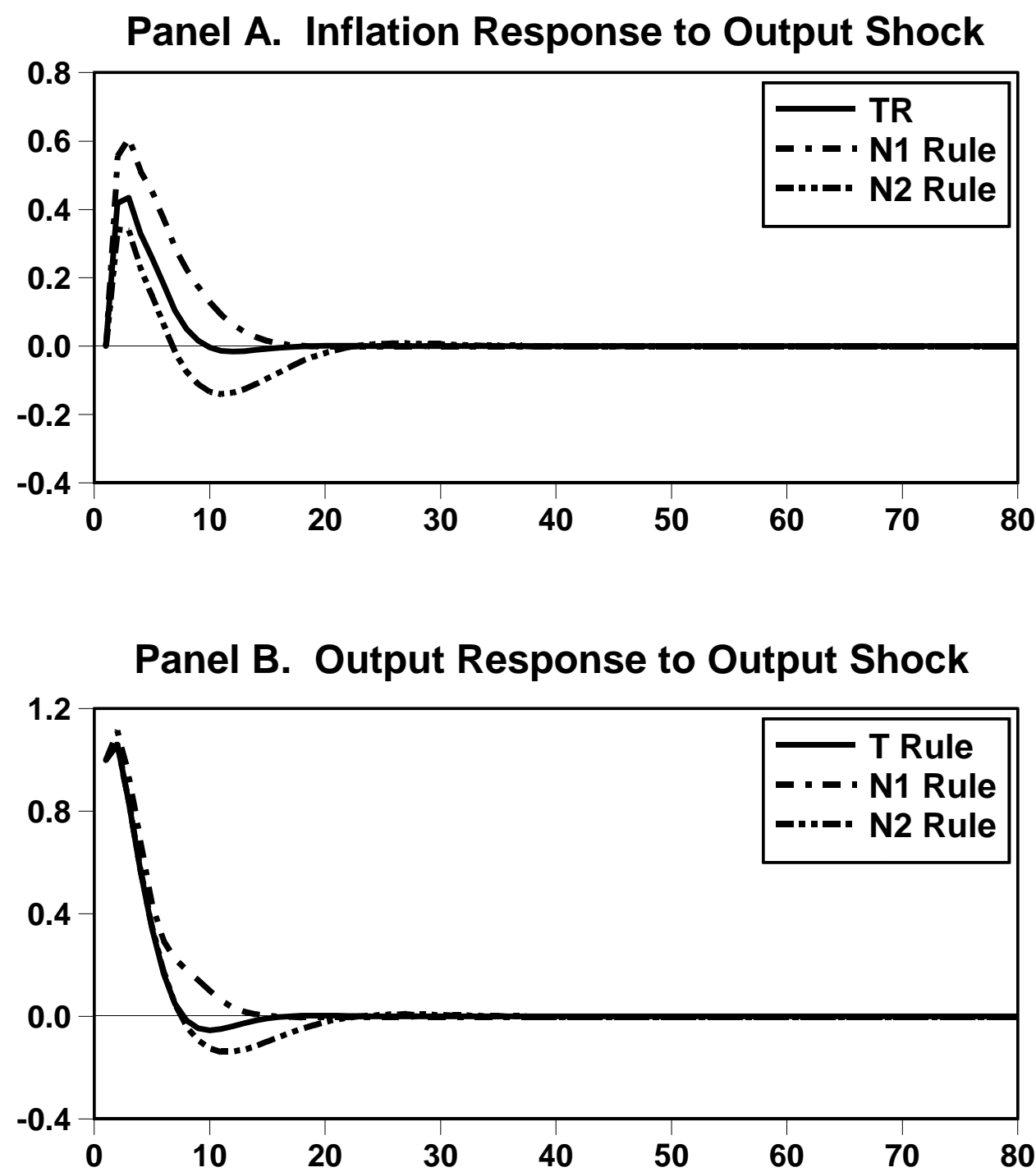

Panel C. Funds Rate Response to Output Shock

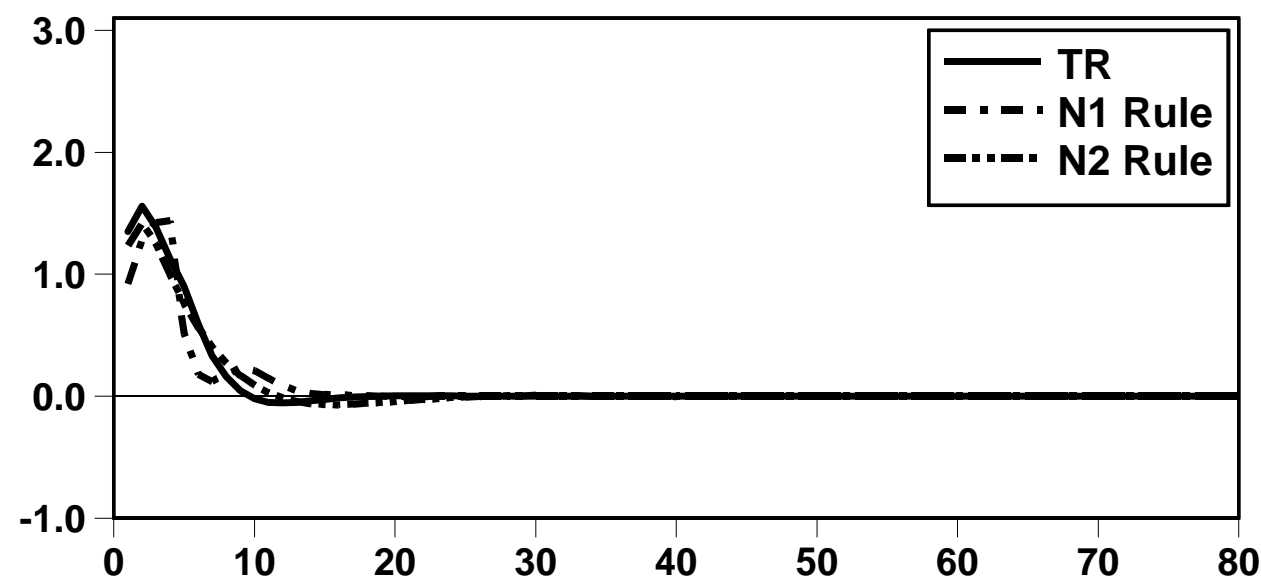


Figure 6

Expected Loss with Alternative Loss Functions
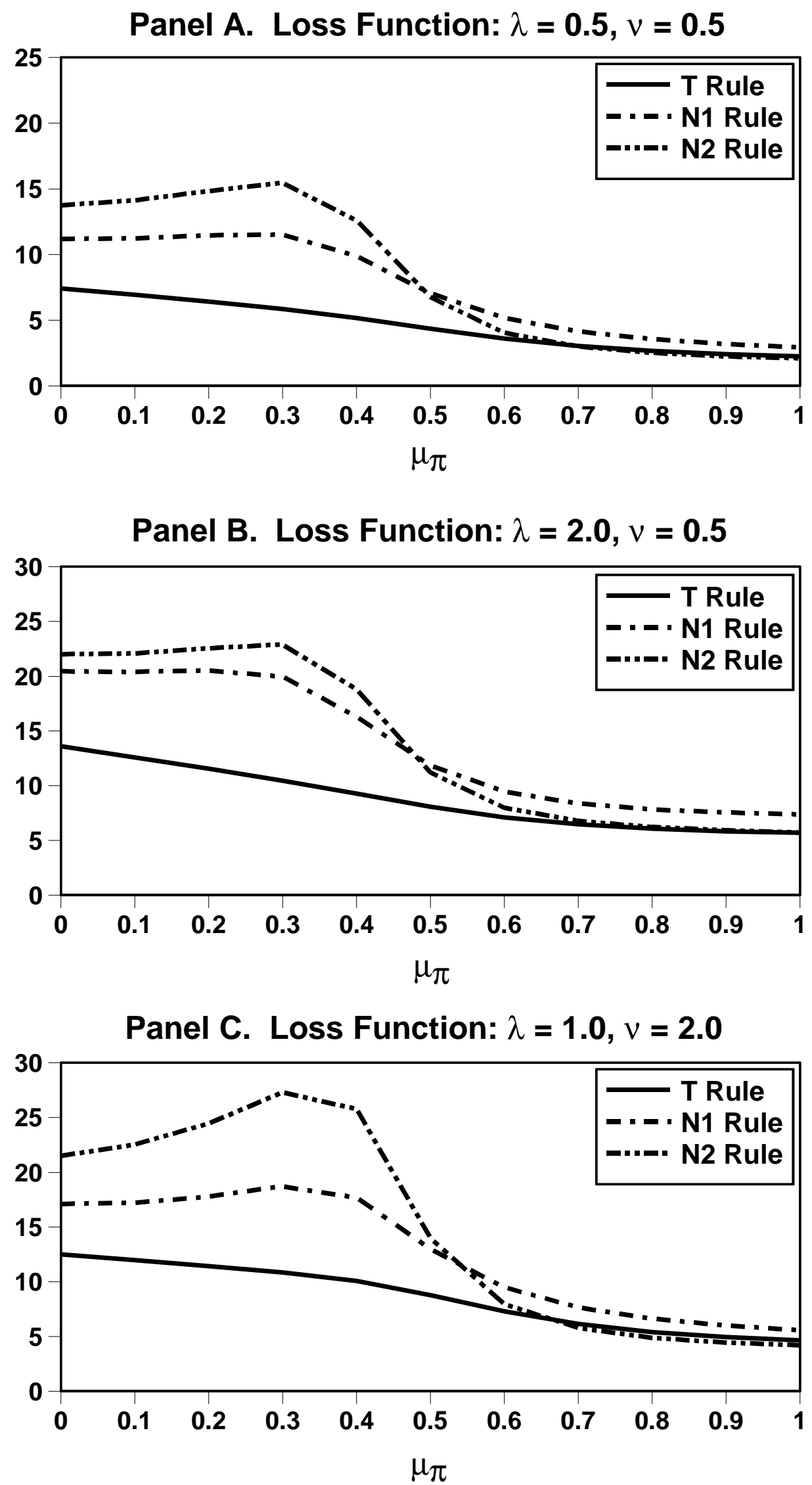


\section{Figure 7 \\ Policy Rule Volatility Frontiers}

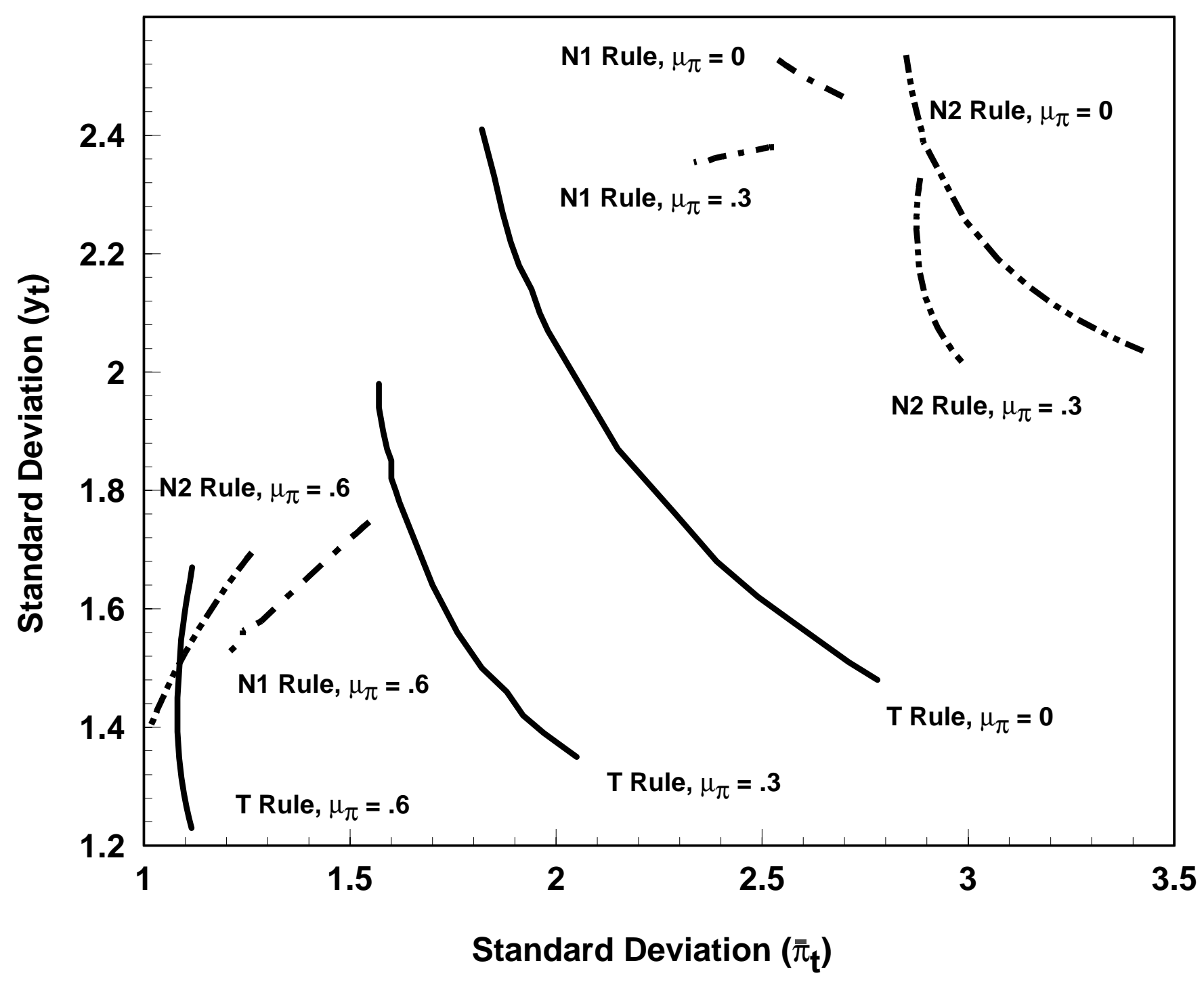


Figure 8

The Robustness of Three Optimized Rules

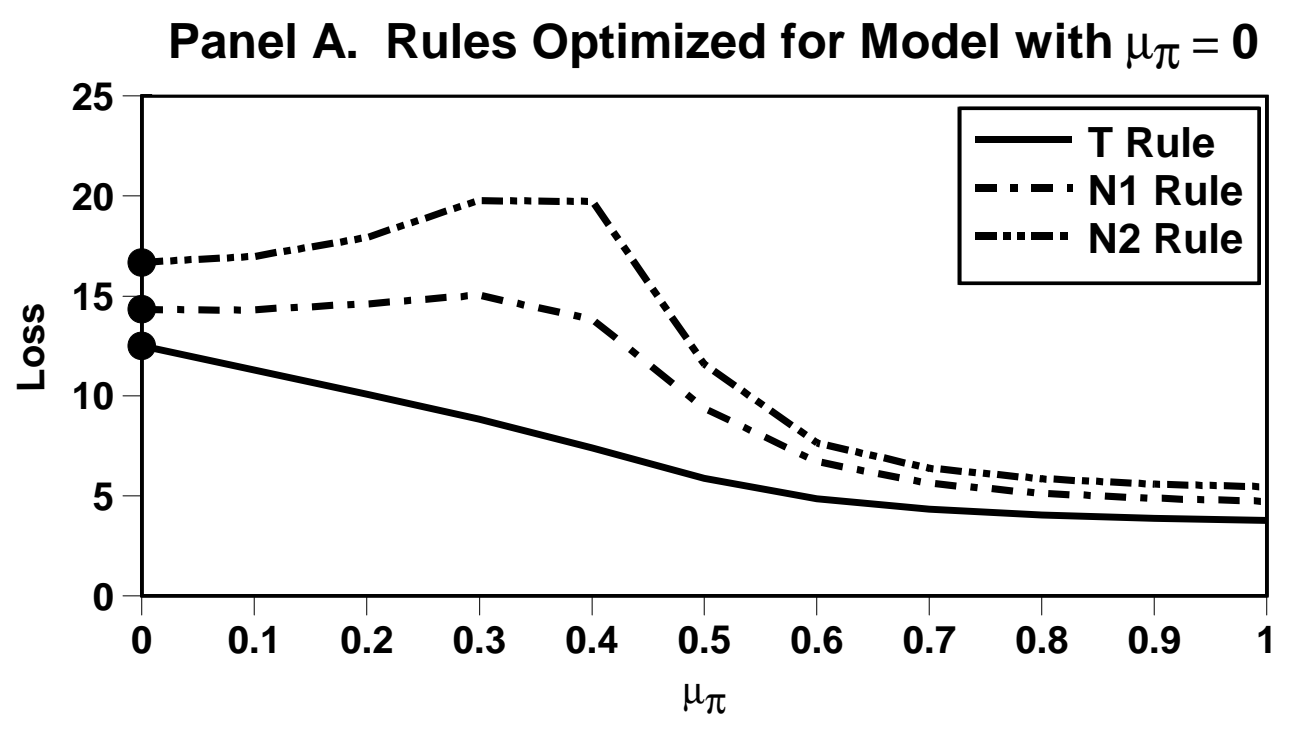

Panel B. Rules Optimized for Model with $\mu_{\pi}=0.3$

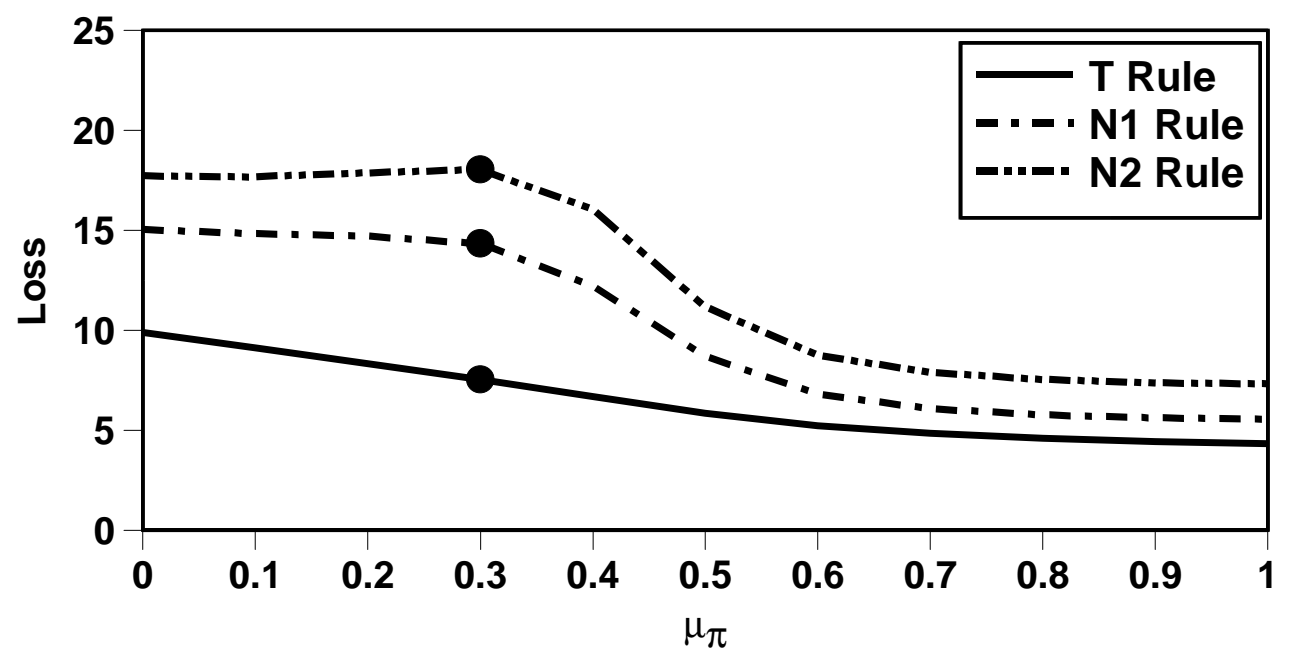

Panel C. Rules Optimized for Model with $\mu_{\pi}=0.6$

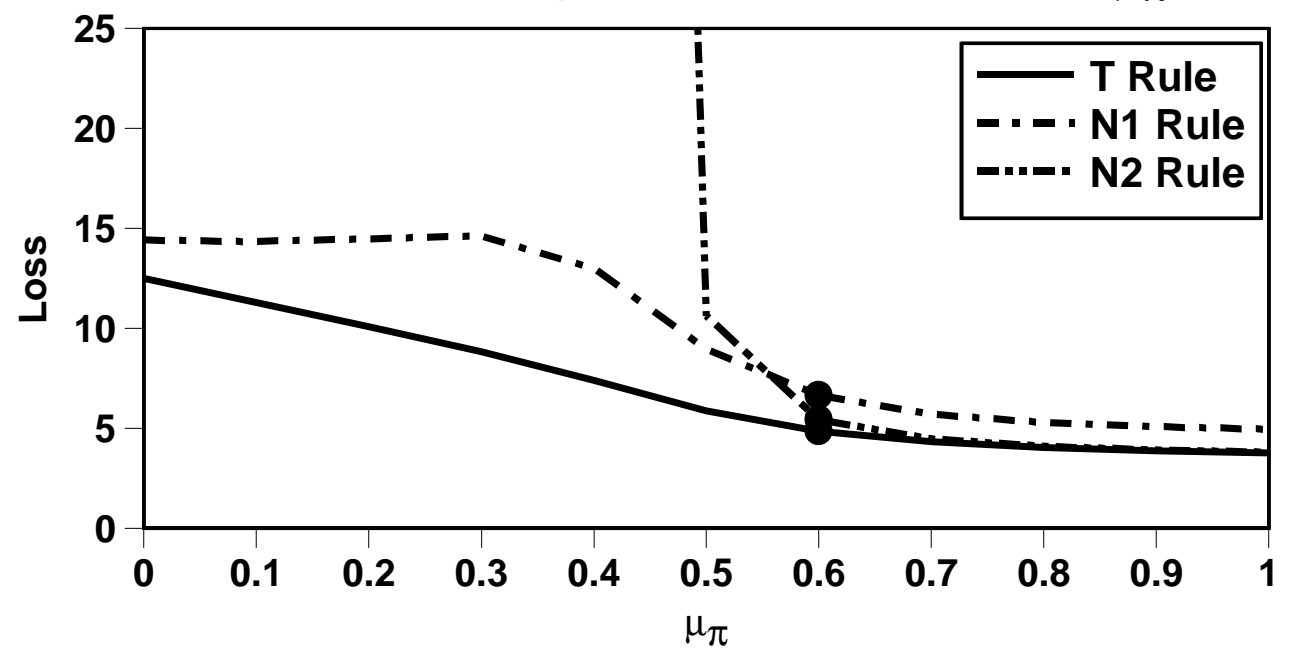


Figure 9

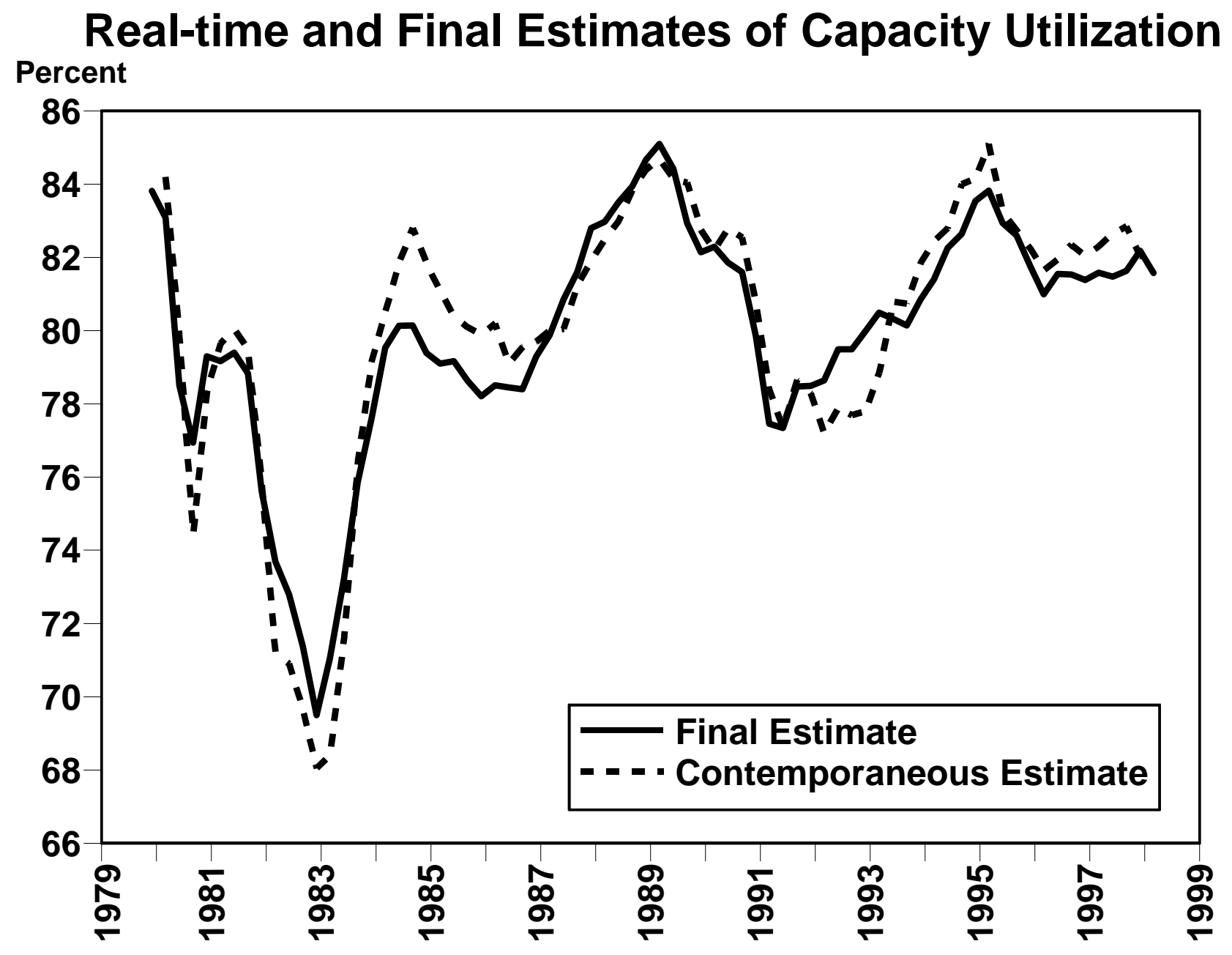


Figure 10

Expected Loss with Real-Time Ouput Gap
and Model Uncertainty

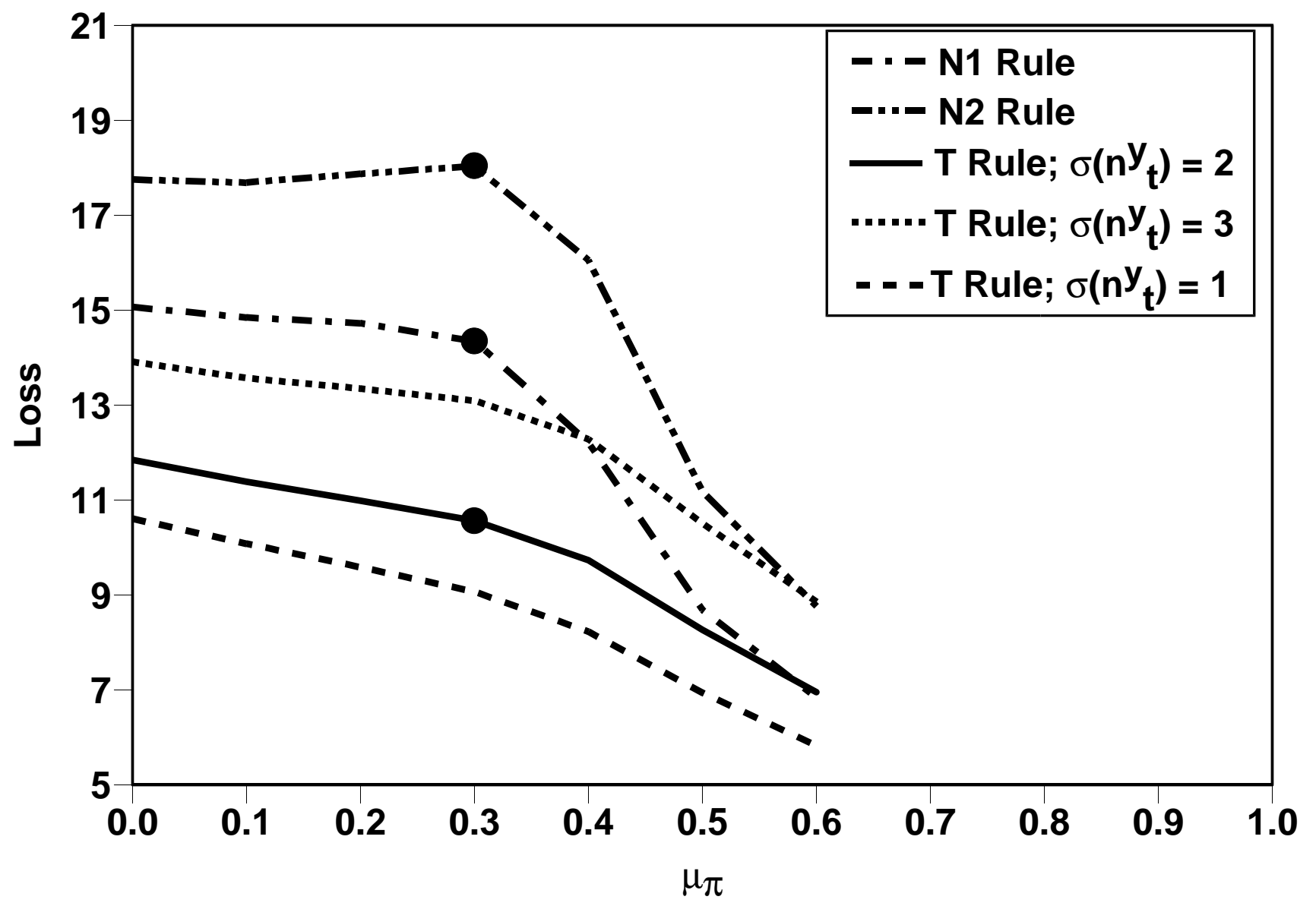

